\title{
OPEN Monitoring atmospheric particulate matters using vertically resolved measurements of a polarization lidar, in-situ recordings and satellite data over Tehran, Iran
}

\begin{abstract}
Hossein Panahifar ${ }^{1 凶}$, Ruhollah Moradhaseli² \& Hamid Reza Khalesifard ${ }^{1,3}$
The highly polluted atmosphere above Tehran has been investigated by using a polarization lidar operating at $532 \mathrm{~nm}$, in-situ particulate matter suites distributed over the city, and meteorological observations. The measurement campaign is conducted from Nov. 2014 to Jan. 2016. Three typical cases are studied in detail where, the atmosphere is polluted with urban pollution, mixture of urban pollution and dust particles from local sources, and long range transported dust from the Arabian Peninsula. For these cases, vertical profiles of the lidar backscatter coefficient, extinction coefficients, particle depolarization ratio $\left(\delta_{\mathrm{p}}\right)$ and mass concentrations of atmospheric aerosols (separated into dust and non-dust particles) are presented. Using the lidar recordings, variations of the planetary boundary layer height above the city are investigated along the year. During November to February, lidar profiles frequently show polluted boundary layers that are reaching up to $1 \mathrm{~km}$ above the ground level. The depolarization ratio $\left(\delta_{\mathrm{p}}\right)$ varies between 0.04 and 0.08 in the polluted boundary layer. During the campaign, for 103 days the urban pollution was dominant, 45 recorded dust events $\left(0.15<\delta_{\mathrm{p}}<0.20\right)$ were originated from the dry regions in the south of Tehran and 15 dust events $\left(0.20<\delta_{p}<0.35\right)$ impacted the city that were originated from the Arabian Desert and Mesopotamia.
\end{abstract}

Tehran $\left(\sim 35.55^{\circ}-35.83^{\circ} \mathrm{N}, \sim 51.09^{\circ}-51.59^{\circ} \mathrm{E}\right)$ is the capital and the most populated city in Iran. More than 13.2 million inhabitants are living in the Tehran metropolitan area ${ }^{1}$. Air pollution is a major environmental issue for the city and particulate matter (PM) concentrations frequently exceed healthy levels based on the world health organization (WHO) standards ${ }^{2}$. Intense urbanization, industrialization, and increase of fossil fuel usage lead to almost permanent aerosol loading in the whole atmosphere of the city ${ }^{3,4}$. This high aerosol load from local sources beside meteorological factors such as stable atmosphere and temperature inversion leads to severe air pollution in Tehran ${ }^{5}$.

To investigate urban pollution in Tehran, some researches have been done by use of emission models, synoptic meteorological, and in-situ PM concentration measurements. Arhami et al. collected daily $\mathrm{PM}_{2.5}$ samples at main stations in Tehran from Feb. 2014 until Feb. 2015. They characterized chemical compositions of the samples and assess the major source categories in Tehran. Their research showed that dominant components of the $\mathrm{PM}_{2.5}$ in weight are: organic matters (35\%), dust (25\%), non-sea salt sulfates (11\%), elemental carbon (9\%), ammonium (5\%) and nitrate (2\%). They also identified 5 major sources responsible for $81 \%$ of the fine PM variations including industrial sources, combustion sources, residual oil combustion, vehicles, and soil dust ${ }^{6}$. Shahbazi et al. developed a traffic-related emission inventory of Tehran using a combination of traffic and emission rates modeling. Their results indicate that driving cars are main sources for emission of carbon monoxide (CO), volatile organic compounds (VOC), nitrogen oxides (NOx), and sulfur oxides $(\mathrm{SOx})^{7}$. Furthermore, Zawar-Reza et al. used of spatio-temporal emission pattern of particulate matters recorded by in-situ PM monitoring stations and concluded that vehicles' traffic and meteorological conditions are responsible for escalations in particulate matter concentrations ${ }^{8}$. The city of Tehran also lies in the middle of the global dust belt ${ }^{9,10}$, so in addition to

\footnotetext{
${ }^{1}$ Department of Physics, Institute for Advanced Studies in Basic Sciences, Zanjan 4513766731, Iran. ${ }^{2}$ Physics Department, Faculty of Science, Zanjan Branch, Islamic Azad University, Zanjan, Iran. ${ }^{3}$ Center for Research in Climate Change and Global warming, Institute for Advanced Studies in Basic Sciences, Zanjan 4513766731, Iran. ${ }^{\boxplus}$ email: h.panahifar@iasbs.ac.ir
} 

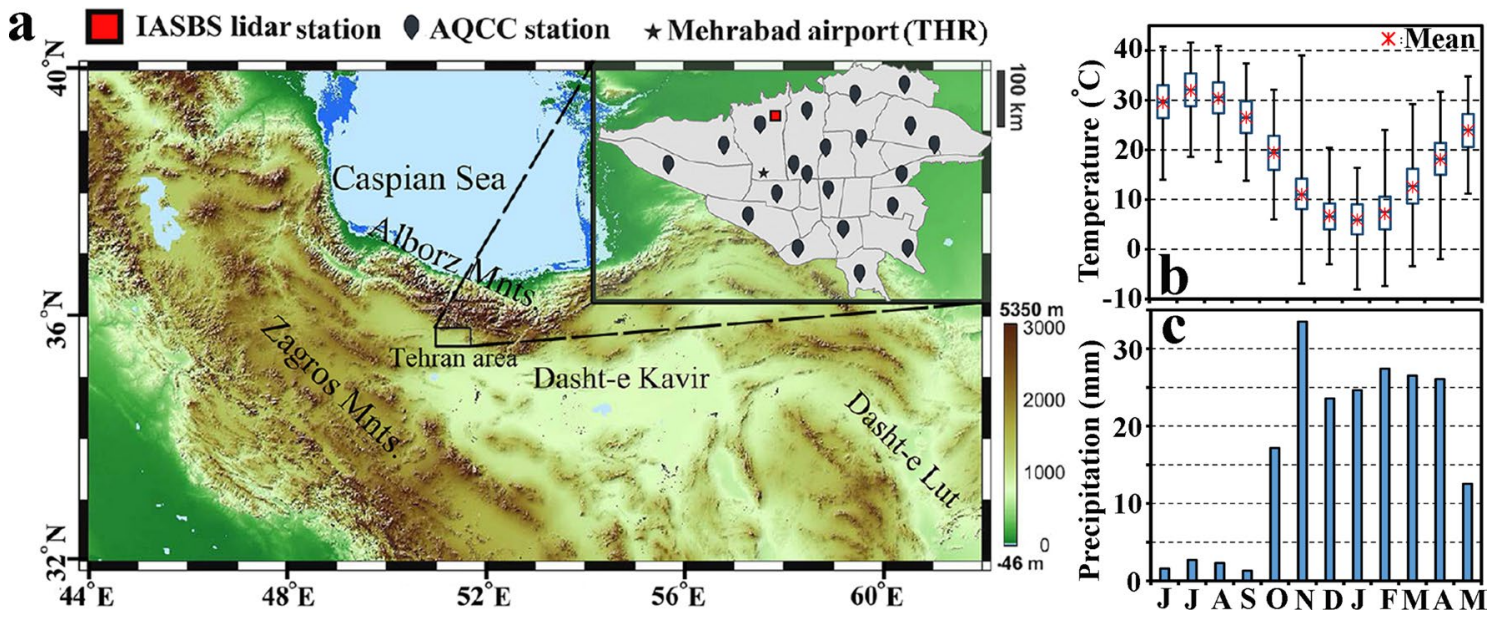

Figure 1. (a) Orography of the northern part of Iran provided by Shuttle Radar Topography Mission project (SRTM), the location of lidar (red square), the Mehrabad synoptic station (black asterisk, WMO code: OIII) and the AQCC stations (black balloons) in municipal district of Tehran. (b) Boxplot of temperature $\left({ }^{\circ} \mathrm{C}\right)$, lower and upper box boundaries 25th and 75th percentile respectively, line inside box indicates median, lower and upper lines shows maximum and minimum respectively and red stars show the mean of data. (c) Monthly average of precipitation $(\mathrm{mm})$ at Mehrabad stations between 2010 and 2018.

urban pollution, it is highly probable to be affected by dust storms originated from either local or trans-regional sources especially during spring and summer ${ }^{11-14}$. To identify sources and transport paths of mineral dust masses to Tehran's atmosphere, some studies have been conducted by use of in-situ and synoptic meteorological data, satellite data analysis, aerosol tracking models, and 3-D numerical modeling of aerosols dispersion ${ }^{15-17}$. All above-mentioned studies revealed valuable information about the particle types and concentrations at ground level, but still do not provide any information about vertical profile of the atmospheric particulate matters.

To provide insight into vertical distribution of atmospheric aerosols, lidar measurements are quite powerful $^{18-22}$. Li et al. studied planetary-boundary-layer-height (PBLH) variation using automated lidar and ceilometers (ALC) in the New York city and explored the correlation with $\mathrm{PM}_{2.5}$ measured at ground level. They found a strong inverse relation between the $\mathrm{PBLH}$ and $\mathrm{PM}_{2.5}$ concentration during the morning transition period in the New York city ${ }^{21}$. Filioglou et al. conducted lidar measurements in the United Arab Emirates and reported lidar ratio of $42 \pm 5 \mathrm{sr}$ and depolarization ratio of $31 \pm 2 \%$ at $532 \mathrm{~nm}$ for the Arabian dust ${ }^{19}$. Hofer et al. performed comprehensive lidar measurements in Dushanbe, Tajikistan. They reported lidar ratio of $36 \pm 2 \mathrm{sr}$ and depolarization ratio of $31 \pm 2 \%$ at $532 \mathrm{~nm}$ for the Arabian dust transported to Central Asia ${ }^{20}$. Heese et al. used the Polly ${ }^{X T}$ lidar to investigate highly polluted atmosphere over the Pearl River Delta, Guangzhou, China ${ }^{22}$. For urban pollution aerosol, they reported lidar ratios of 30 to $80 \mathrm{sr}$ with a mean value of $48.0 \pm 10.7 \mathrm{sr}$ at $532 \mathrm{~nm}$. In that report, the linear particle depolarization ratio at $532 \mathrm{~nm}$ for urban pollution lies mostly below $5 \%$, with a mean value of $3.6 \pm 3.7 \%$. Burton et al. also used recordings of a high spectral resolution lidar equipped with polarization channels, and classified different atmospheric aerosols based on their intensive parameters including the lidar ratio, depolarization ratio and backscatter color ratio ${ }^{23}$.

For the first time, in this work we are reporting results of thirteen months of lidar measurements on atmospheric aerosols in Tehran. The research includes vertically resolved polarization lidar measurements supported by space-borne remote sensing data as well as synoptic meteorological and in-situ PM concentration measurements. The polarization lidar technique permits the discrimination of desert dust from urban pollution and other aerosol types ${ }^{22-26}$. This research provides valuable information about the aerosol vertical distribution, boundary layer height variations, aerosol typing based on the particle linear depolarization ratio $\left(\delta_{\mathrm{p}}\right)$ of lidar signal, and source apportionment of particulate matter in the atmosphere above Tehran. So that a clear view regarding natural and anthropogenic aerosol contributions to the overall aerosol conditions is possible. This paper includes three sections while "Observation site and methodology" is dedicated to explanation of the observation site, methodologies of the measurements and data-set. Lidar measurements and obtained results are discussed in "Results and discussions", and the paper ends with a summary and conclusion in "Summary and conclusion".

\section{Observation site and methodology}

Climatology of Tehran, ground-based facilities, calculation techniques, satellite data and atmospheric models that have been used in this study are described in the following.

Tehran climatology. Tehran is located in the northern part of the Iran Plateau $\left(\sim 26^{\circ}-35^{\circ} \mathrm{N}, \sim 46^{\circ}-61^{\circ} \mathrm{E}\right)$ and on the foothills of Alborz mountains. Figure 1a shows the regional orography and geographical location of Tehran, as well as locations of measurement sites including IASBS lidar station (red square), Mehrabad synoptic station (black star) and Air Quality Controlling Company (AQCC) stations (black balloons). Figure 1a illustrates that the greater Tehran metropolitan is more expanded toward the west and south. The region also is faced to Alborz mountains in its north side. The existence of such a high altitude barrier affects the wind and dispersion 


\begin{tabular}{|c|c|c|}
\hline \multicolumn{3}{|l|}{ Transmitter } \\
\hline \multirow{6}{*}{ Laser } & Type & Frequency doubled pulsed Nd:YAG \\
\hline & Model & Quantel, Ultra CFR \\
\hline & Energy per pulse at $1064 \mathrm{~nm} / 532 \mathrm{~nm}(\mathrm{~mJ})$ & $50 / 30$ \\
\hline & Repetition Rate (Hz) & $1-20$ \\
\hline & Divergence (mrad) & $<6$ \\
\hline & Pulse duration (ns) & 10 \\
\hline \multirow{4}{*}{ Beam expander } & Type & Galilean Geometry \\
\hline & Model & Thorlabs, LC2632 \\
\hline & Beam expansion ratio & $10 \times$ \\
\hline & Divergence of expanded laser beam (mrad) & $<1$ \\
\hline \multicolumn{3}{|l|}{ Receiver } \\
\hline \multirow{4}{*}{ Telescope } & Type & Modified Cassegrian Geometry \\
\hline & Model & VIXEN, VMC200L \\
\hline & Primary mirror diameter $(\mathrm{mm})$ & 200 \\
\hline & Effective Focal length $(\mathrm{mm})$ & 1950 \\
\hline \multirow{3}{*}{ Photomultiplier } & Parallel channel & ElectronTubes $9789 \mathrm{QB}$ \\
\hline & Perpendicualr channel & Electrontubes 9658B \\
\hline & Cross talk between parallel and perpendicular receiving channels (\%) & $<1$ \\
\hline \multicolumn{3}{|c|}{ Signal acquisition system } \\
\hline \multirow{4}{*}{ Oscilloscope } & Type & Digital oscilloscope \\
\hline & Model & Tektronix, TDS3054 \\
\hline & Maximum count rate $(\mathrm{MHz})$ & 350 \\
\hline & Time bin width (ns) & 20 \\
\hline
\end{tabular}

Table 1. Technical specification of the portable polarization lidar.

pattern of pollutants over Tehran. The elevation across the city ranges from $900 \mathrm{~m}$ above mean sea level (amsl) in the south to $1800 \mathrm{~m}$ amsl in the northern part. Such a variation of elevation across the city makes the meteorological conditions quite different at its various points. Tehran's complex topography is one of the factors which aggravates the city air pollution problem.

Variations of monthly averages of surface temperature and precipitation in Tehran are shown in Fig. 1b,c. These data are recorded at the Mehrabad meteorological station (WMO code: OIII) during the years 2010-2018. According to theses results, Tehran has a semi-arid climate ${ }^{27,28}$. Figure $1 \mathrm{~b}$ illustrates that temperature increases up to $43{ }^{\circ} \mathrm{C}$ in July and drop to as low as $-6.5^{\circ} \mathrm{C}$ in January. The minimal rainfall occurs from June to September, and the highest value of monthly averaged precipitation occurs in November (Fig. 1c).

Demographically, Tehran has an estimated 8.7 million inhabitants and the larger Tehran metropolitan with 16 sub-provinces has a population estimated at 13.2 million ${ }^{1}$. Although roughly $11 \%$ of Iran's total population lives in the city of Tehran, they consume more than 20 million liters of fuel per day which is $22 \%$ of total fuel consumption in Iran. According to reports by the statistical center of Iran, there are around 4 million cars, 3 million motorcycles, and around 20 million daily trips in the city ${ }^{1}$.

Ground-based measurements. An elastic backscatter polarization lidar operating at $532 \mathrm{~nm}$ is used as the main ground-base remote sensing instrument in this research. The lidar station is located at $35.7669^{\circ} \mathrm{N}$, $51.3118^{\circ} \mathrm{E}$, at an altitude of $1430 \mathrm{~m}$ amsl in the northwest of Tehran and inside the urban area (Fig. 1a). The measurement campaign lasted from Nov. 2014 until Jan. 2016. The lidar was working continuously in 24/7 operation mode except during precipitation conditions, electricity failures and repair of the lidar components. There are total of 357 days of lidar measurements during campaign. Technical specifications of the lidar are summarized in Table 1 . The lidar is constructed in a bi-axial structure and the transmitter-receiver complete overlap starts at $150 \mathrm{~m}$ above the ground level (agl). The lidar transmitter repetition rate is $2 \mathrm{~Hz}$ and its data are captured with vertical resolution $12 \mathrm{~m}$ and stored with a temporal resolution $7 \mathrm{~min}$. Based on the specifications of the optical and electronic elements that have been used in the detection unit of the lidar, the cross talk between parallel and perpendicular channels is less than $1.0 \%$.

The Mehrabad meteorological station (OIII) is located at the distance of $8 \mathrm{~km}$ toward the south of the lidar station and mostly has the same distance to the central district of Tehran. Regular synoptic and upper air measurements are carrying at the Mehrabad station. Radiosonde balloons are lunching twice a day at 00:00 and 12:00 UTC at this station and measuring altitude, vertical profile of pressure, temperature, relative humidity (RH) and wind (both wind speed and wind direction) at specific pressure levels. In surface observation section, the horizontal visibility $(\mathrm{HV})$, temperature, wind speed and direction, the $\mathrm{RH}$ and precipitation amounts are measured every $3 \mathrm{~h}$ and are used in this study.

Tehran Air Quality Control Company (AQCC) data are also used as another ground-based in-situ measurement. During the measurement campaign, the AQCC was using of 21 automated air monitoring stations and 


\begin{tabular}{|c|c|c|c|c|}
\hline \multirow[b]{2}{*}{ Aerosol type } & \multicolumn{3}{|l|}{ Parameters } & \multirow[b]{2}{*}{ References } \\
\hline & Lidar ratio (sr) & $c_{\mathrm{v}, \lambda}\left(10^{-12} \mathrm{Mm}\right)$ & $\left.\rho\left(\mathrm{g} / \mathrm{cm}^{3}\right)\right)$ & \\
\hline Middle Eastern dust & 40 & 0.79 & 2.6 & $\begin{array}{l}\text { Mamouri et al. }{ }^{54} \text {, Mamouri and Ansmann }{ }^{31} \text {, Filioglou } \\
\text { et al. }{ }^{19}\end{array}$ \\
\hline Urban Pollution & $40-80$ & 0.25 & 1.55 & Hofer et al. ${ }^{20,36}$, Heese et al. ${ }^{22}$, Burton et al. ${ }^{23}$ \\
\hline Salt (dry and wet) & 25 & 0.65 & 1.1 & Haarig et al. ${ }^{37}$, Mamouri and Ansmann ${ }^{30}$ \\
\hline
\end{tabular}

Table 2. Parameters applied to convert particle backscatter coefficient to mass concentration.

measuring concentration of main pollutant species almost continuously. The location of each AQCC station are shown in Fig. 1a. From these measurements, concentrations of carbon oxides $\left(\mathrm{CO}\right.$ and $\left.\mathrm{CO}_{2}\right)$, Nitrogen oxides $\left(\mathrm{NO}\right.$ and $\left.\mathrm{NO}_{2}\right)$ and particulate matter smaller than 10 and 2.5 micrometer $\left(\mathrm{P} M_{10}\right.$ and $\left.\mathrm{P} M_{2.5}\right)$ can be obtained. In this study we just used of the $\mathrm{P} M_{10}$ and $\mathrm{P} M_{2.5}$ recordings. The accuracy of these recordings are $1 \mu \mathrm{g} / \mathrm{m}^{3}$ as reported by the AQCC. All the concentration levels mentioned in this study shows their corresponding hourly averaged values over all AQCC active stations in Tehran.

Retrieval of particle optical properties using lidar measurements. A height-resolved separation of dust and non-dust particles is possible by using recordings on the parallel and perpendicular channels of a polarized-elastic lidar at $532 \mathrm{~nm}$. The methodology is applicable to cases where only two basic types of aerosols exist. It is usually assumed that the atmospheric aerosols are a mixture of dust and non-dust particles. These aerosols should be known in terms of their corresponding depolarization and lidar ratios ${ }^{29-31}$. As the first step, the total particle backscatter coefficient $\left(\beta_{\mathrm{p}}\right)$ that is a sum of backscatter coefficients at parallel and perpendicular channels can be retrieved by applying the Klett-Fernald method ${ }^{32}$. Then, as it is shown by Freudenthaler et al., the particle depolarization ratio $\left(\delta_{p}\right)$ is computed using the measured volume depolarization ratio $\left(\delta_{\mathrm{V}}\right)$ and the derived particle backscatter coefficient $\left(\beta_{\mathrm{p}}\right)^{33}$. Afterward using the procedure proposed by Tesche et al., the profile of the total particle backscatter coefficient can be decomposed to dust and non-dust components $\left(\beta_{\mathrm{d}}\right.$ and $\beta_{\text {nd }}$ ) through the Eqs. $1 \mathrm{a}-\mathrm{c}^{26}$ :

$$
\begin{gathered}
\beta_{\mathrm{d}}=\beta_{\mathrm{p}} \frac{\left(\delta_{\mathrm{p}}-\delta_{\mathrm{nd}}\right)\left(1+\delta_{\mathrm{d}}\right)}{\left(\delta_{\mathrm{d}}-\delta_{\mathrm{nd}}\right)\left(1+\delta_{\mathrm{p}}\right)} \text { for } \delta_{\mathrm{nd}}<\delta_{\mathrm{p}}<\delta_{\mathrm{d}}, \text { and } \beta_{\mathrm{nd}}=\beta_{\mathrm{p}}-\beta_{\mathrm{d}} \\
\beta_{\mathrm{d}}=\beta_{\mathrm{p}} \text { for } \delta_{\mathrm{p}} \geq \delta_{\mathrm{d}} \\
\beta_{\mathrm{nd}}=\beta_{\mathrm{p}} \text { for } \delta_{\mathrm{p}} \leq \delta_{\mathrm{nd}}
\end{gathered}
$$

To solve Eq. 1a, the dust depolarization ratio $\left(\delta_{\mathrm{d}}\right)$ and the non-dust depolarization ratio $\left(\delta_{\text {nd }}\right)$ should be presumed as 0.31 and 0.05 respectively ${ }^{29-31}$. In the final step, as shown by Mamouri et al., the mass concentrations of dust $\left(M_{\mathrm{d}}\right)$ and non-dust $\left(M_{\mathrm{nd}}\right)$ particles can be obtained by applying appropriate values for particle density $(\rho)$, extinction-to-volume conversion factors $\left(c_{\mathrm{v}, \lambda}\right)$ and lidar ratio $(\mathrm{S})$ through the Eq. $2^{31,34}$ :

$$
\begin{gathered}
M_{\mathrm{d}}=\rho_{\mathrm{d}} c_{\mathrm{v}, d, \lambda} \beta_{d} \mathrm{~S}_{d} \\
M_{\mathrm{nd}}=\rho_{\mathrm{nd}} c_{\mathrm{v}, \mathrm{nd}, \lambda} \beta_{\mathrm{nd}} S_{\mathrm{nd}}
\end{gathered}
$$

The parameters applied to convert particle backscatter coefficient of different aerosol types to corresponding mass concentration are listed in Table $2^{19,20,22,23,30,31,35-37}$.

Planetary boundary layer height calculation. To have a better understanding of atmospheric pollution episodes in Tehran, the planetary boundary layer height (PBLH) is retrieved from lidar recordings ${ }^{38,39}$. Prior to any processing on range corrected lidar signal on the parallel channel $\left(S(R)_{\|}\right)$, an algorithm is applied to improve the signal-to-noise ratio. This algorithm is based on shark smell optimization method ${ }^{40}$, and is very important to apply it before running the algorithm to find the boundary layer height. Between 150 and $1000 \mathrm{~m}$ agl, the sliding average is performed over each 840 lidar signals ( 7 min of recording). After averaging, the second derivative of $S(R)_{\|}$with respect to the range has been calculated and its minimum is taken as the top of the boundary layer. The relative error on the retrieved PBLH is between 5 and $10 \%$ depending on the atmospheric conditions, and higher errors correspond to more clean atmosphere. It should be noted that the cloud layers also may show the same behavior on the second derivative, but usually they are appearing at higher altitudes. The obtained PBLH by this technique is in good agreement with the boundary layer derived from radiosonde ascents via the Richardson method $^{39}$.

Satellite data and atmospheric models. The regional distribution and transport of dust aerosols are described using following satellite products. The collection 6 of MODIS level-3 daily products with resolution $1^{\circ} \times 1^{\circ}$ are used to monitor the aerosol loading over the study region and influential sources ${ }^{41}$. These products include aerosol optical depth (AOD) at $550 \mathrm{~nm}$ (MOD08-MYD08) and deep blue Ängström Exponent for land $(412-470 \mathrm{~nm})$. The MCD19A2 data product with resolution $1 \times 1 \mathrm{~km}$, which is a Multi-Angle Implementa- 


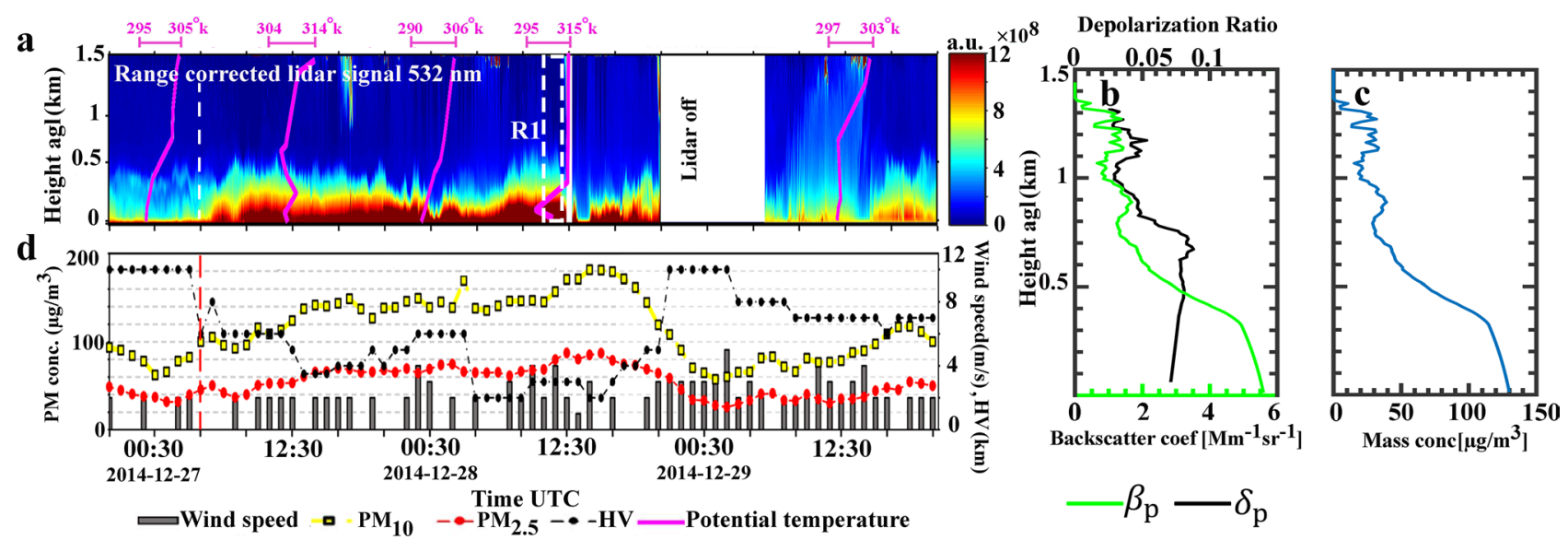

Figure 2. (a) Parallel channel time-height series of range corrected lidar signal at $532 \mathrm{~nm}$ from 20:30 UTC 26 Dec. to 20:30 UTC 29 Dec. 2014 and potential temperature vertical profiles. (b) Derived particle backscatter coefficient (green) and particle depolarization ratio (black) at $532 \mathrm{~nm}$ for 11:00 to 12:00 UTC, 28 Dec. 2014 (R1 in Fig. 2a). (c) Mass concentration profile obtained from lidar measurement for period same as Fig. 2b with assumed $\rho_{\text {nd }}=1.55 \mathrm{~g} / \mathrm{cm}^{3}, c_{\mathrm{v}, \mathrm{nd}, \lambda}=0.25 \times 10^{-12} \mathrm{Mm}$ and $S_{\mathrm{nd}}=60 \mathrm{sr}$. (d) Temporal evolution of the horizontal visibility (HV) and surface wind speed recorded at the Mehrabad synoptic station and hourly averages of PM concentrations reported by the AQCC Tehran. The approximate start time of the pollution episode is shown by the white and red dashed lines in $(\mathbf{a}, \mathbf{d})$.

tion of Atmospheric Correction (MAIAC) algorithm-based on Level-2 gridded (L2G) aerosol optical thickness product also has been used in this study ${ }^{42}$. Details of MODIS Deep Blue aerosol optical depth uncertainties are reported by Sayer et al. ${ }^{43}$. CALIOP retrieved aerosol depolarization ratio and aerosol subtype are compared with ground-base lidar measurements ${ }^{44,45}$. In the "Supplement Movie", the emission and subsequent transport of dust plumes are shown in the RGB dust composite. This products is produced by use of three IR channels of Spinning Enhanced Visible and Infrared Imager (SEVIRI) on Meteosat Second Generation (MSG) payload. Dust appears pink or magenta in this RGB combination. The full disc view includes the whole of Europe, all of Africa and Middle East and allows frequent sampling every $15 \mathrm{~min}$, with a spatial resolution of $3 \mathrm{~km}$ in the nadir ${ }^{46}$. The basic atmospheric parameters such as wind speed and direction at different pressure levels which are used in this research produced by the global atmospheric reanalysis model, ERA-Interim, produced by the European Centre for Medium-Range Weather Forecasts (ECMWF) ${ }^{47,48}$. The back-trajectories are calculated with the NOAA Hybrid Single Particle Lagrangian Integrated Trajectory (HYSPLIT) model $^{49}$.

\section{Results and discussions}

The following results and discussions are based on lidar measurements carried out in Tehran from Nov. 2014 to Jan. 2016. To illustrate frequently observed layers in the atmosphere above Tehran, three cases are presented in "Case studies". The monthly variation of boundary layer height, air quality index, and surface wind speed are presented in "Boundary layer height evolution". Source apportionment and aerosol type categorization are also discussed in "Source apportionment".

Case studies. To describe the variety of observed aerosol layers in Tehran, three illustrative cases are discussed in the following subsections. In these cases, the particle backscatter coefficient and particle linear depolarization ratio are retrieved based on method described in "Retrieval of particle optical properties using lidar measurements". To separate dust and non-dust backscatter coefficients, as Mamouri et al. assumed, we use values of 0.31 and 0.05 for dust and non-dust depolarization ratio $\left(\delta_{\mathrm{d}}\right.$ and $\left.\delta_{\mathrm{nd}}\right)$. The mass concentration profiles are also calculated and Table. 2 used in different cases for setting the conversion factors. The first case, 26-29, December 2014 , is representing a period in which the atmosphere of Tehran was heavily polluted with anthropogenic aerosols. The second case, 12-15, December 2014 is a situation comprises of a mixture of urban pollution and dust from local sources. The process of emission and long-range transport of dust plumes from the Arabian Peninsula and Mesopotamia to Tehran are discussed as the last case, 22 April 2015.

Case 1: 26-29 December 2014. In this case, the lidar was in operation from 26 until 29 Dec. 2014, during the development of an air pollution episode in Tehran. By comparison of lidar and other ground-based recordings, it can be deduced that the pollution episode started at 04:30, 27 Dec. and lasted until 20:30 UTC, 28 Dec. 2014. The approximate time in which the pollution episode starts is shown by the white and red dashed lines in Fig. 2a,d. Air quality guidelines for particulate matter from the WHO stipulates that 24-h mean of $\mathrm{P} M_{2.5}\left(\mathrm{PM}_{10}\right)$ concentrations should not exceed $25(50) \mu \mathrm{g} / \mathrm{m}^{32}$, while mean of $\mathrm{P} M_{2.5}\left(\mathrm{P} M_{10}\right)$ concentrations are $\sim 60(128)$ $\mu \mathrm{g} / \mathrm{m}^{3}$ during air pollution episode.

The time-height variations of the range corrected lidar signal for the parallel channel at $532 \mathrm{~nm}$ are shown in Fig. 2a. The figure spans the time interval of 20:30 UTC, 26 Dec. until 20:30 UTC, 29 Dec. 2014. The vertical 
a
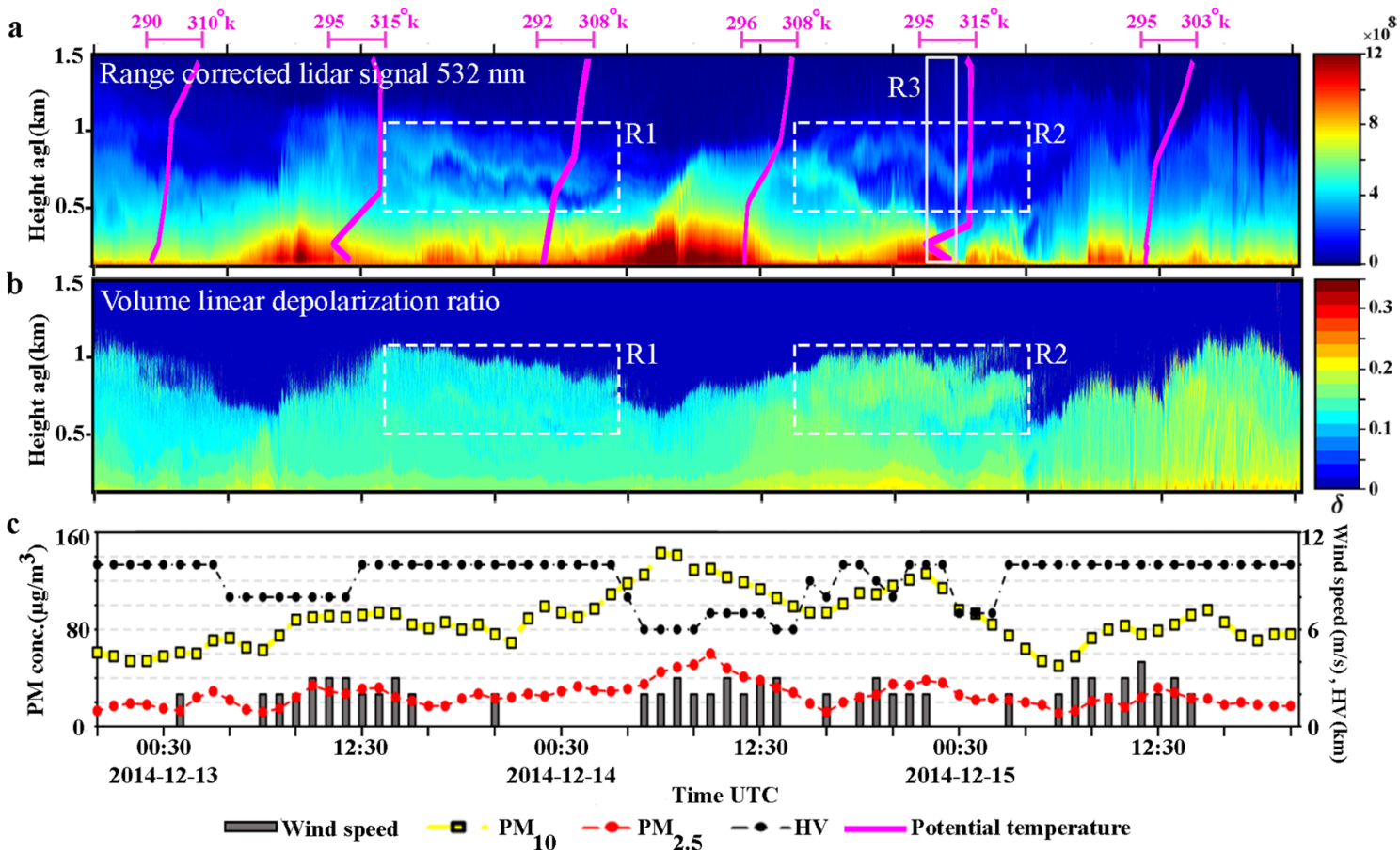

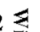

Figure 3. (a, b) Parallel channel and volume depolarization ratio time-height series of range corrected lidar signal at $532 \mathrm{~nm}$. (c) Temporal evolution of the horizontal visibility (HV) and surface wind speed recorded at the Mehrabad synoptic station and hourly averages of PM concentrations reported by the AQCC Tehran, 20:30 UTC, 12 Dec. to 20:30 UTC, 15 Dec. 2014.

profiles of potential temperature are also shown by pink lines in Fig. 2a. It is evident that the potential temperature for most of the time either increases or stays constant with height and this leads to statically stable atmospheres ${ }^{50}$. Figure 2a depicts an atmospheric temperature inversion up to $\sim 700 \mathrm{~m}$ agl and even a quite stable atmosphere at higher altitudes at 00:00 UTC on 27 December. The lidar time series (Fig. 2a) clearly shows that after 04:30 UTC on 27 Dec., the strength of lidar signals from near surface layer gradually increases. Vertical profiles of the potential temperatures show that the atmosphere remains stable during the whole pollution episode.

Vertical profiles of optical properties and mass concentration of atmospheric aerosols, for $1 \mathrm{~h}$ averaged lidar signal (R1 in Fig. 2a), are shown in Fig. 2b,c. The total particle backscatter coefficient is retrieved by applying the Klett method and shown by the green line in Fig. 2 b. Considering that only anthropogenic particles exist in the atmosphere, an initial constant lidar ratio of $60 \mathrm{sr}$ are assumed for these particles. Generally, pollution particles are relatively small, spherical, and highly absorbing that produce low depolarization and large lidar ratios ${ }^{22,23,25}$. The retrieved particle backscatter coefficient profile also shows that the pollution is trapped in a $\sim 500 \mathrm{~m}$ thick boundary layer. This is also in agreement with the potential temperature profile (pink line in R1, Fig. 2a) that shows an inversion layer extended from surface to $\sim 200-500 \mathrm{~m}$ agl. The particle linear depolarization ratio at $532 \mathrm{~nm}$ (black line in Fig. 2b) is $\sim 0.07$ for the polluted boundary layer, which confirms that this aerosol layer is barely depolarizing the lidar signals. The computed particle depolarization ratio $\left(\delta_{\mathrm{p}} \sim 0.07\right)$ is comparable with non-dust depolarization ratio $\left(\delta_{\text {nd }} \sim 0.05\right)$. So it can be deduced that the urban pollution is dominant in the atmosphere. Finally, the mass concentration profile is calculated by Eq. $2 \mathrm{~b}$ where values of $\rho_{\mathrm{nd}}, c_{\mathrm{v}, \mathrm{nd}, \lambda}$ and $S_{\mathrm{nd}}$ for urban pollution are obtained from Table. 2 . The calculated mass concentration is largest $\left(\sim 130 \mu \mathrm{g} / \mathrm{m}^{3}\right)$ at near surface and gradually decreases by height. Figure $2 \mathrm{~d}$ depicts that the $\mathrm{P} M_{2.5}\left(\mathrm{P} M_{10}\right)$ concentrations reaches to $\sim 80(150) \mu \mathrm{g} / \mathrm{m}^{3}$ at 12:00 UTC, 28 December 2014. Noting that the PM values are averaged over the city, the mass concentration retrieved from lidar measurements is in a good agreement with in-situ measurements.

As the pollution episode starts, the horizontal visibility at the Mehrabad station drops to $\sim 6 \mathrm{~km}$ and even falls to $\sim 2 \mathrm{~km}$ in the last hours of pollution episode. The surface wind speed is almost less than $3 \mathrm{~m} / \mathrm{s}$ during the whole episode. After 20:30 UTC, 28 Dec. precipitation starts in the city and the lidar is turned off. The rainfall makes the atmosphere clean and $\mathrm{PM}_{2.5}\left(\mathrm{PM}_{10}\right)$ drops to below $40(80) \mu \mathrm{g} / \mathrm{m}^{3}$ and the horizontal visibility increases to $10 \mathrm{~km}$ (Fig. 2d). This typical case shows how the development of an atmospheric inversion in coincidence with slow surface wind makes the atmosphere quite stable and traps the urban pollution below $\sim 500 \mathrm{~m}$ agl (Fig. 2a). The HYSPLIT backward trajectories (not shown here) also confirm that atmospheric aerosols for such cases should be originated from local sources. These kinds of events are occurring very frequently in the late autumn and winter times in the atmosphere above Tehran.

Case 2: 12-15 December 2014. Temporal evolution of range corrected lidar signals for the parallel channel, and time-height developments of the volume depolarization ratio for this case are depicted in Fig. 3a,b respectively. Lidar time series are recorded from 20:30 UTC, 12 Dec. to 20:30 UTC, 15 Dec. 2014. Vertical profiles of potential temperature captured at the Mehrabad station are also shown by pink lines in Fig. 3a. The diurnal cycle and 


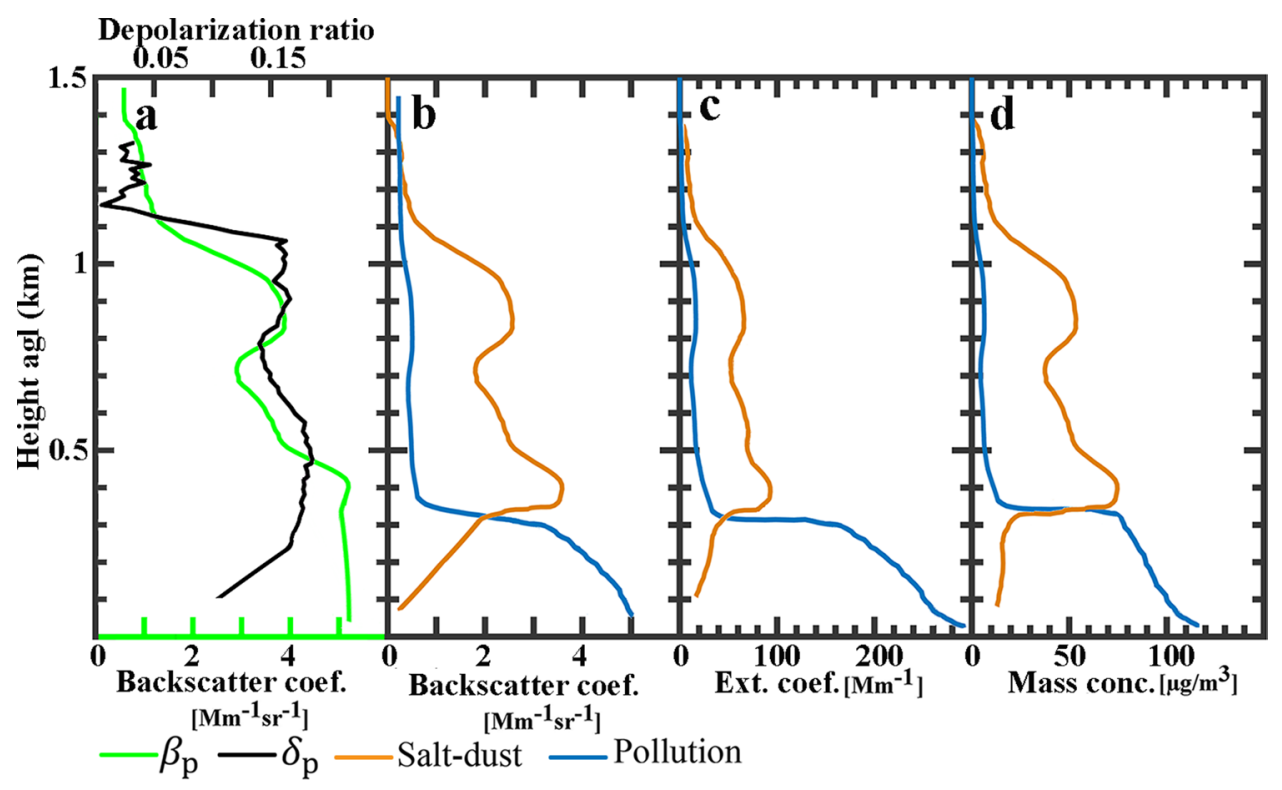

Figure 4. Optical and physical properties of atmospheric aerosols retrieved from averaged lidar signals at $532 \mathrm{~nm}$ during 23:00 to 24:00 UTC, 14 Dec. 2014, (R3 in Fig. 3a). (a) Particle backscatter coefficient (green) and depolarization ratio (black). (b) Backscatter coefficient for salt-dust (orange) and pollution (blue) particles. (c) Extinction coefficient for salt-dust and pollution particles by multiplying the backscatter coefficients in Fig. $4 \mathrm{~b}$ with the lidar ratio of $25 \mathrm{sr}$ for salt-dust and $60 \mathrm{sr}$ for pollution. (d) Mass concentration profile obtained from lidar measurement for period same as in Fig. $4 \mathrm{~b}$ with assumed $\rho_{\text {salt }}=1.1 \mathrm{~g} / \mathrm{cm}^{3}, c_{\mathrm{v}, \text { salt }, \lambda}=0.65 \mathrm{Mm}$ for saltdust and $\rho=1.55 \mathrm{~g} / \mathrm{cm}^{3}, c_{\mathrm{v}, \mathrm{nd}, \lambda}=0.25 \times 10^{-12} \mathrm{Mm}$ for pollution.

the developments of polluted boundary layer on 13 and 14 Dec., are evident on lidar recordings (Fig. 3a). These polluted layers are associated with high emission of anthropogenic aerosols during Tehran rush hours. Vertical profiles of the potential temperature during 13-14 Dec., beside the surface wind speed which blows very slowly (Fig. 3c), confirm that the atmosphere is completely stable. Atmospheric stability leads to an increase in concentrations of particulate matter close to ground level and eventually escalates the strength of backscatter lidar signals. Rectangles R1 and R2 in Fig. 3a include two layers with quite similar behavior. On the other hand, Fig. 3b clearly illustrates that these layers have different volume depolarization ratio. The volume depolarization ratio is $\sim 0.1$ for layer inside $\mathrm{R} 1$ and $\sim 0.2$ for layer inside $\mathrm{R} 2$.

Some of vertically resolved optical and physical properties of atmospheric aerosols during 23:00 to 24:00 UTC on 14 Dec. 2014 (R3 in Fig. 3a) are shown in Fig. 4. The particle backscatter coefficient (green line in Fig. 4a) is retrieved by applying the Klett method to $1 \mathrm{~h}$ averaged lidar signals. The backscatter coefficient profile shows a double-layer structure for atmospheric aerosols. The first layer is the polluted boundary layer and extended from surface up to $\sim 500 \mathrm{~m}$ agl. Also a thin aerosol layer is detected at $\sim 900 \mathrm{~m}$ agl. The particle depolarization ratio (black line in Fig. 4a) is also computed and the double-layer structure is clear in its profile. The depolarization ratio is less than $\sim 0.10$ for polluted boundary layer, and it is $\sim 0.17$ for the second layer. Figure $4 \mathrm{~b}$ shows the backscatter coefficient profiles of the detected aerosol layers after their decomposition into dust and non-dust particles (Eq. 1). The orange line in Fig. 4b shows two layers of dust particles at $\sim 400 \mathrm{~m}$ and $\sim 900 \mathrm{~m}$ agl.

The HYSPLIT model and complementary satellite data have been used to determine the source and type of dust particles inside R3. The 72h HYSPLIT backward trajectories started at 15:00 UTC, 14 Dec. 2014, at altitudes of $900 \mathrm{~m}$ agl and $400 \mathrm{~m}$ agl are shown in Fig. 5. Both trajectories are returning back to deserts in the south of Tehran or northern boarder of Dasht-e-Kavir desert where the dried Qom-Salt-Lake is located. Particles that may rise from the dried bed of such lakes or their coastal area contains considerable amounts of mineral salts and we call such types of particles as salt-dust ${ }^{51}$. Figure 5 shows that the lower trajectory almost rounds the lake and the upper one is crossing over its northern part. On the other hand, Fig. 5a,b illustrate daily MODIS deep blue AODs with $1 \mathrm{~km}$ resolution (MCD19A2 product) and deep blue Ängström exponent (AE) with $1^{\circ}$ resolution on 13 Dec. 2014, respectively. These figures depict that the AOD increase $(0.4 \leq \mathrm{AOD} \leq 0.6)$ and Ängström Exponent decrease (AE 0.5) over the dried salt lake on 13 Dec. 2014. The increase (decrease) of the AOD (AE) indicate an increase in the loading of coarse-mode particles over the lake ${ }^{52}$. Referring to Fig. 5, we may conclude that the observed dust layers inside R2 in Fig. 3a are originated from the dry regions in the south of Tehran where a dry salt lake also exists.

Noting to the particle depolarization ratio (black line in Fig. $4 \mathrm{a}, \delta_{\mathrm{p}} \sim 0.17$ ) and the expected source of dust particles, we concluded that these might be some types of salt-dust particles and by referring to the work by Haarig et al., a lidar ratio of $S=25 \mathrm{sr}$ is considered for them ${ }^{37}$. The respective extinction coefficients for salt-dust and non-dust particles (Fig. 4c) are obtained by multiplying the backscatter coefficient profiles with the lidar ratio of $25 \mathrm{sr}$ for salt-dust and $60 \mathrm{sr}$ for pollution particles. Having in hand all required input parameters of Eq. 2, $\left(\rho_{\text {salt }}=1.1 \mathrm{~g} / \mathrm{cm}^{3}, c_{\mathrm{v}}\right.$, salt, $\lambda=0.65 \times 10^{-12} \mathrm{Mm}$ for salt-dust and $\rho_{\text {nd }}=1.55 \mathrm{~g} / \mathrm{cm}^{3}, c_{\mathrm{v}, \text { nd }, \lambda}=0.25 \times 10^{-12} \mathrm{Mm}$ 

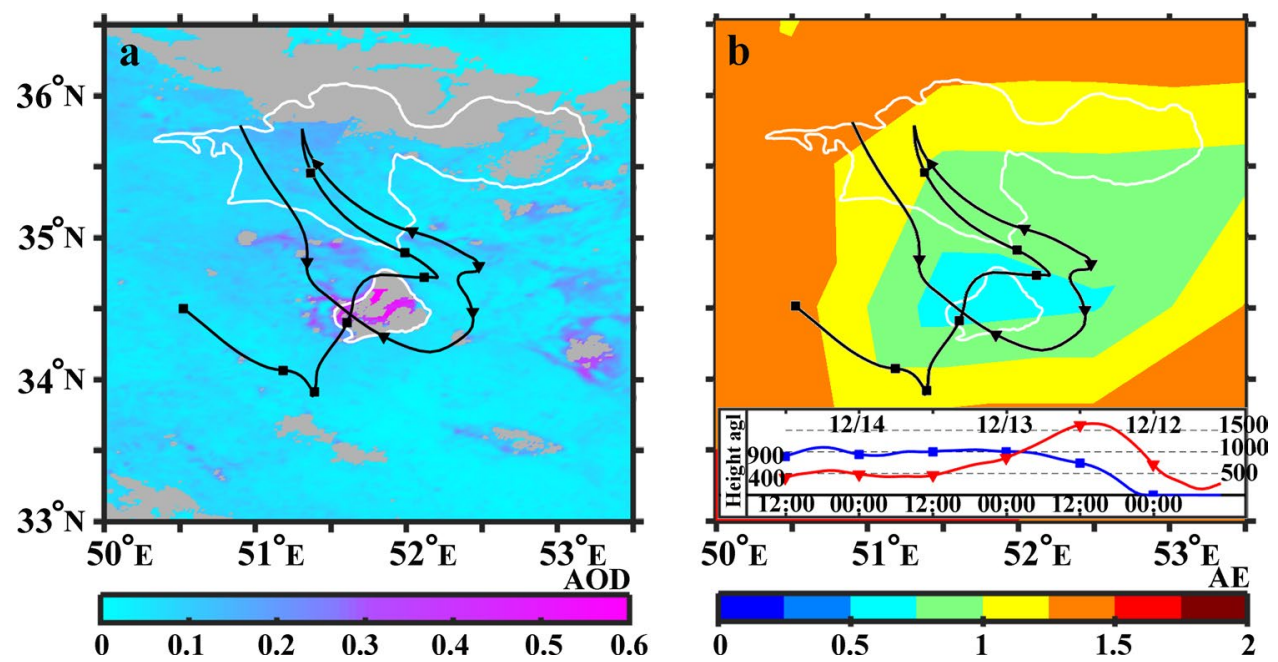

Figure 5. (a) 72 hour HYSPLIT backward trajectories arriving at lidar station at 15:00 UTC, 14 Dec 2014 at $900 \mathrm{~m}$ and $400 \mathrm{~m}$ agl height overlaid on MODIS daily Deep blue AODs with $1 \mathrm{~km}$ resolution (MCD19A2 product) on $13 \mathrm{Dec} 2014$, Grey pattern means no data regions. (b) Same back-trajectories as part (a) overlaid on Deep blue Ängström exponent on 13 Dec 2014. HYSPLIT heights and dates information are similar for both parts and shown in part (b).
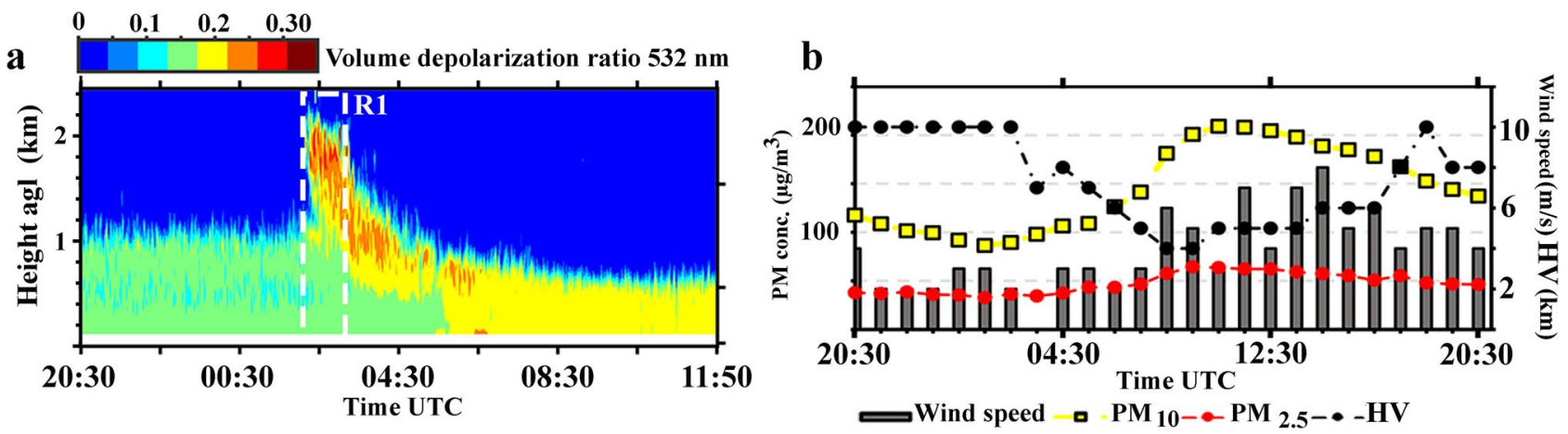

Figure 6. (a) Volume depolarization ratio time-height series at 532nm between 20:30 UTC, 21 April until 11:50 UTC on 22 April 2015. (b) Temporal evolution of the horizontal visibility (HV) and surface wind speed recorded at the Mehrabad synoptic station and hourly averages of PM concentrations reported by the AQCC Tehran, on 22 April 2015.

for non-dust particles) concentration profiles of salt-dust and non-dust particles are retrieved and depicted in Fig. 4 d. The obtained mass concentration of particles at ground level $\left(M_{\mathrm{nd}} \sim 116 \mu \mathrm{g} / \mathrm{m}^{3}\right)$, is in agreement with the obtained averaged $\mathrm{P} M_{10}$ concentration value for the same time period in Fig. $3 \mathrm{c}\left(\mathrm{P} M_{10} \sim 120 \mu \mathrm{g} / \mathrm{m}^{3}\right)$. As a conclusion, the existence of particles having depolarization ratios $\sim 0.17$ which is close to that of salt particles ${ }^{37}$, suggests that the emission of salt-dust particles from dried Qom-Salt-Lake have an impact on the aerosol contents of the Tehran's atmosphere. Lidar observations have been conducted by Hofer et al. also reveals that direct emission and transport of resuspended salt dust originated from desiccating lakes have a sensitive impact on the aerosol background optical properties over Dushanbe, Tajikistan ${ }^{53}$.

Case 3: 22 April 2015. An elevated dust layer originated from the Arabian Peninsula and regions in the south of Iraq is transported toward Tehran and arrived to the city on 22 April 2015. The time-height development of the volume depolarization ratio at $532 \mathrm{~nm}$ is shown in Fig. 6a. The time-series have been recorded from 20:30 UTC, 21 April to 11:50 UTC, 22 April 2015. This storm caused a power outage in the city and the lidar is turned off at 11:50 UTC. The arrived dust layer is observed at altitudes of 500-2500 m agl around 02:30 UTC on 22 April, and in the following hours, the dust layer is descending toward the surface. Figure $6 \mathrm{~b}$ illustrates as the dust storm slams the city, the surface wind speed and $\mathrm{P} M_{10}$ concentration simultaneously raise to higher than $8 \mathrm{~m} / \mathrm{s}$ and $200 \mu \mathrm{g} / \mathrm{m}^{3}$ respectively. All these developments cause horizontal visibility drops to lower than $4 \mathrm{~km}$ at the Mehrabad station.

The vertical profiles of optical properties and mass concentration are retrieved by performing the approach described in "Retrieval of particle optical properties using lidar measurements" on 1 h averaged lidar signals (R1 in Fig. 6a) and its results are shown in Fig. 7. The total particle backscatter coefficient (green line in Fig. 7a) is 


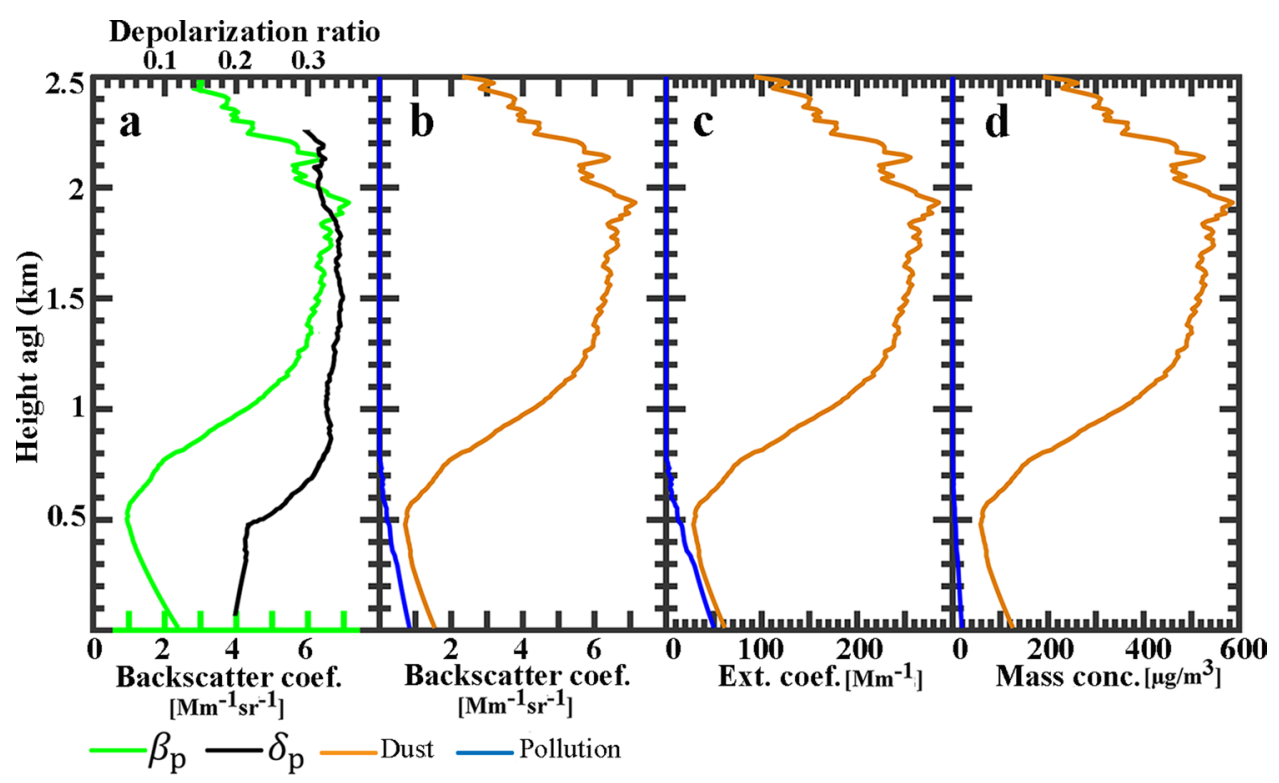

Figure 7. Optical and physical properties of atmospheric aerosols retrieved from averaged lidar signals at $532 \mathrm{~nm}$ during 02:00 to 03:00 UTC, 22 April 2014, (R1 in Fig. 6a). (a) Particle backscatter coefficient (green) and depolarization ratio (black). (b) Backscatter coefficient for dust (orange) and pollution (blue) particles. (c) Extinction coefficient for dust and pollution particles by multiplying the backscatter coefficients in Fig. 6b with the lidar ratio of $40 \mathrm{sr}$ for dust and $60 \mathrm{sr}$ for pollution. (d) Mass concentration profile obtained from lidar measurement for period same as in (b) with assumed $\rho_{\mathrm{d}}=2.6 \mathrm{~g} / \mathrm{cm}^{3}, c_{\mathrm{V}}, \mathrm{d}, \lambda=0.79 \times 10^{-12} \mathrm{Mm}$ for dust and $\rho_{\mathrm{nd}}=1.55 \mathrm{~g} / \mathrm{cm}^{3}, c_{\mathrm{v}, \mathrm{nd}, \lambda}=0.25 \times 10^{-12} \mathrm{Mm}$ for pollution.

retrieved using the Klett method by considering lidar ratio 40 sr that is reported for Middle Eastern dust ${ }^{35,54}$. The backscatter coefficient profile shows that the main dust layer extended between 500 and $2500 \mathrm{~m}$ agl. The particle depolarization ratio (black line in Fig. $7 \mathrm{a}$ ) is on average $\sim 0.2$ for the first $500 \mathrm{~m}$ above the ground, and it is on average $\sim 0.31$ for the main dust layer. So it is concluded that the main layer consists of pure dust particles with depolarization ratio of $0.30-0.35$ at $532 \mathrm{~nm}^{35,54}$. Knowing that the boundary layer should be polluted with urban pollution, dust and non-dust particles are separated by the technique presented in "Retrieval of particle optical properties using lidar measurements", and the resolved dust and pollution backscatter coefficient profiles are presented in Fig. 7b. The respective extinction coefficients (Fig. 7c) are obtained by multiplying the backscatter coefficients (in Fig. 7b) with the lidar ratio of $40 \mathrm{sr}$ for dust and $60 \mathrm{sr}$ for pollution particles. Finally, the mass concentration profiles (Fig. $7 \mathrm{~d}$ ) is obtained by applying appropriate values for particle densities and extinction-to-volume conversion factors for dust and urban pollution from Table 2 . The mass concentration profile shows that dust mostly contributes to particle mass concentration profile from $500 \mathrm{~m}$ to $2500 \mathrm{~m}$ agl, while non-dust particles extended from surface up to $500 \mathrm{~m}$ agl. The dust mass concentration reaches to a maximum of $\sim 600 \mu \mathrm{g} / \mathrm{m}^{3}$ at $\sim 1.9 \mathrm{~km}$ agl.

The emission and subsequent transport of this lofted dust layer can be clearly observed and followed in the RGB composite images from MSG-SEVIRI products ("Supplement Movie"). This movie clearly illustrates that the dust plume originates from the Al-Nefud desert in the Arabian Peninsula as well as regions in South Mesopotamia at around 06:00 UTC, 21 April. The subsequent transport of this dust plume toward Tehran is also shown in the "Supplement Movie". The ECMWF reanalysis of surface wind speed and direction at 06:00 UTC, 21 April 2015 (Fig. 8a) reveals that a very strong surface wind which its speed reaches almost to $15 \mathrm{~m} / \mathrm{s}$, blows over Al-Nefud desert and south of Iraq (dashed oval in Fig. 8a). The wind speed exceeds the minimum value of threshold friction velocity and has the potential to activate dust sources in this region ${ }^{55}$. The daily Aqua MODIS deep blue AODs over the region on 21 April 2015 are illustrated in Fig. 8b. Areas with AOD> 1 are mostly located in the region between the north of Saudi Arabia and the south of Iraq which is consistent with the dust source activation in these regions (Fig. 8a). Depolarization ratios from nighttime CALIOP measurements on 21 April 2015 are shown in Fig. 8c. Figure 8b,c reveal that a lofted dust layer (up to $5 \mathrm{~km}$ ) has been formed over the north of Saudi Arabia and the south of $\operatorname{Iraq}\left(\sim 28^{\circ} \mathrm{N}-34^{\circ} \mathrm{N}\right)$. CALIOP recordings are in good consistency with the depolarization ratio measured by our lidar station $\left(\delta_{\mathrm{p}} \sim 0.34\right)$, and it also corroborates the large AOD values observed by MODIS over Iraq and Saudi Arabia (Fig. 8b). The ECMWF reanalysis of the atmospheric vertical velocity at 06:00 UTC, 21 April 2015 on $850 \mathrm{hPa}$ (color) and surface wind speed (arrows) are depicted in Fig. 8d. The atmospheric vertical velocity over the expected source (dashed oval in Fig. 8d) is mainly negative, which is an indicator of an upward movement of air parcels. The wind profile at $850 \mathrm{hPa}$ (Fig. 8e) depicts a very strong south-westerly wind over the source region and clearly confirms that the lofted dust plume subsequently is transferred to the west and central part of Iran. The 72 HYSPLIT backward trajectories started from the lidar station on 22 April 2015 at altitudes of $2500 \mathrm{~m}$ agl and $2200 \mathrm{~m}$ agl are returning back to the Arabian Peninsula and south of the Mesopotamia respectively (Fig. 8f). Daily values of deep blue AODs which are captured by 

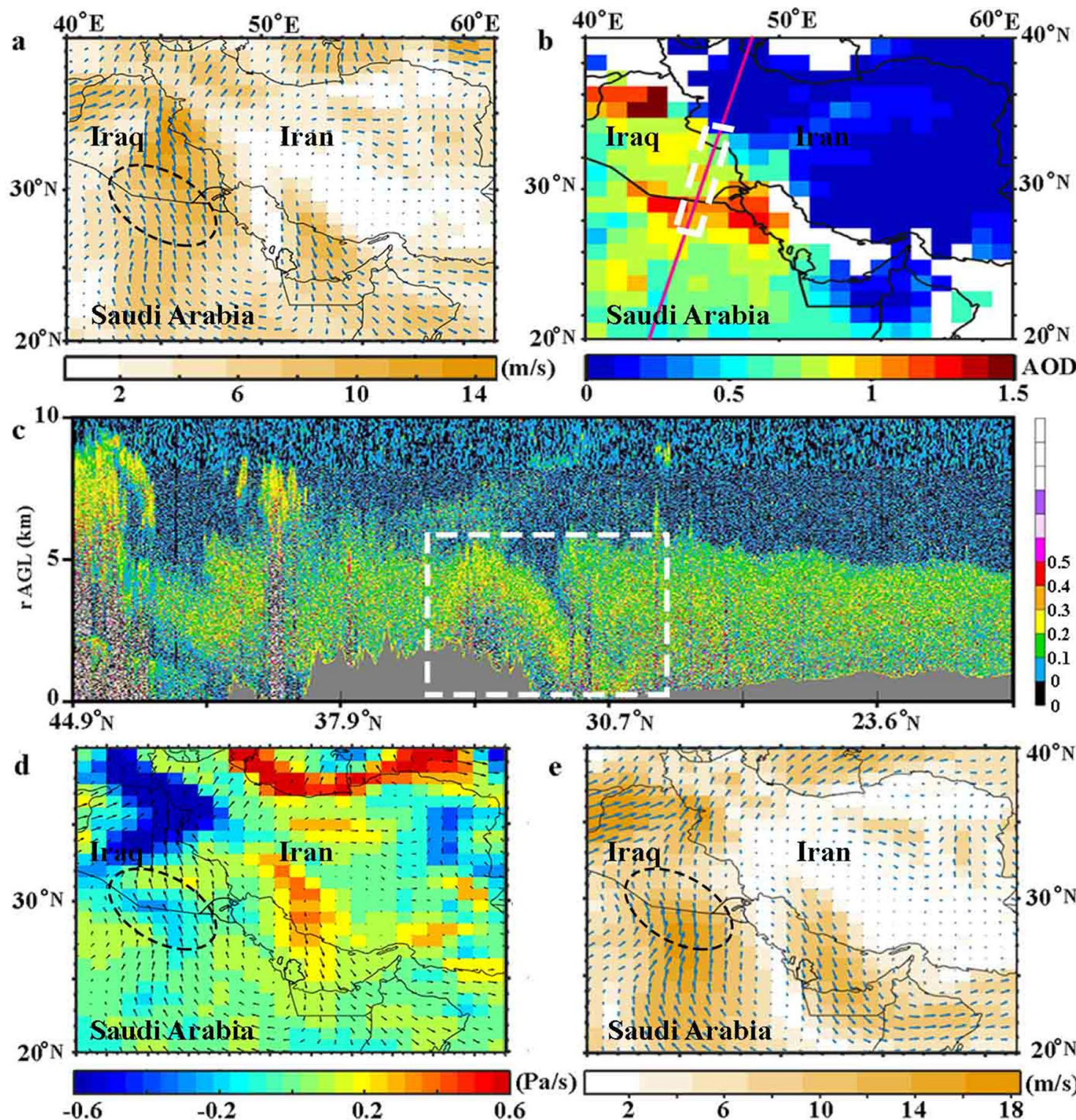

e

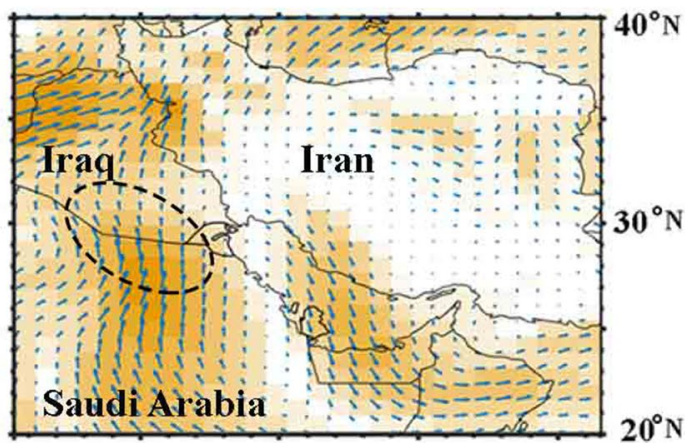

$(\mathrm{Pa} / \mathrm{s})$
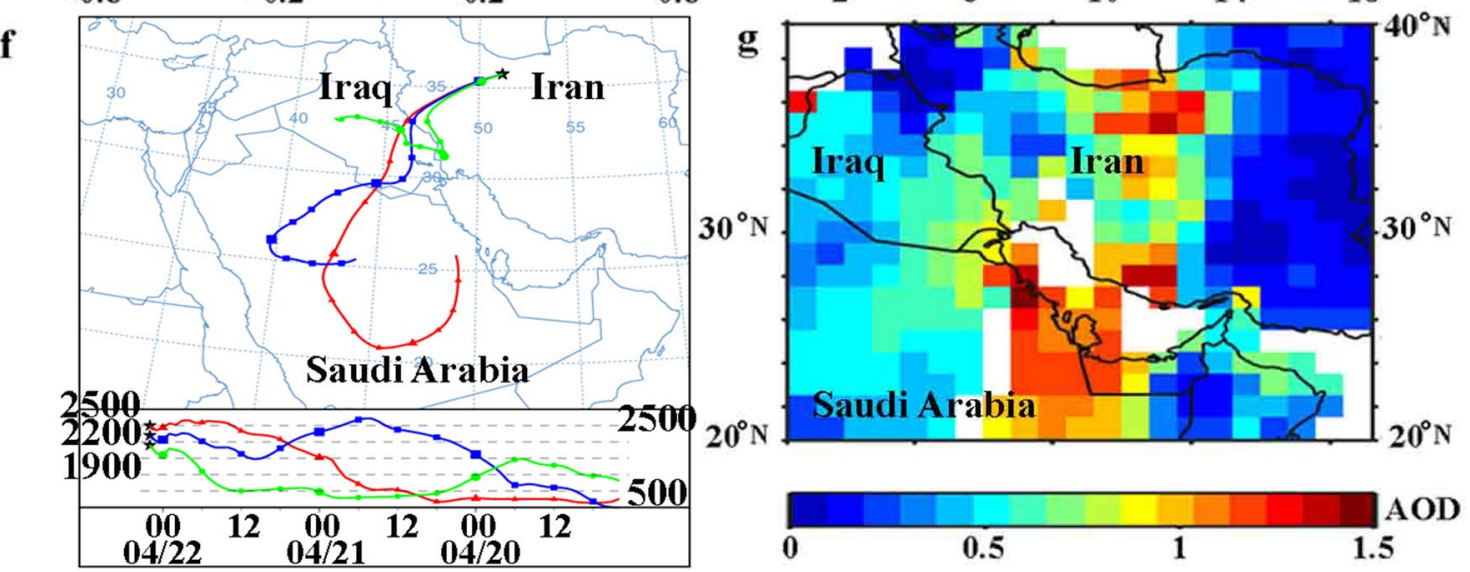

Figure 8. (a) ECMWF reanalysis of surface wind speed (color) and direction (arrows) on 06:00 UTC 21 April 2015. (b) AQUA MODIS daily deep blue AOD at $550 \mathrm{~nm}$ on 21 April 2015 and a daytime CALIPSO groundtrack ( solid red line). (c) Vertical cross section of CALIOP depolarization ratio at $532 \mathrm{~nm}$ on 21 April 2015. (d) Same as part (a) but at $850 \mathrm{hPa}$. (e) ECMWF atmospheric vertical velocity at $850 \mathrm{hPa}$ (color) and wind direction (arrows) on 06:00 UTC 21 April 2015. (f) 72-h HYSPLIT backward trajectories arriving to Tehran at 02:00 UTC on 22 April 2015 at 2500 m, $2200 \mathrm{~m}$ and $1900 \mathrm{~m}$ heights. (g) TERRA MODIS daily deep blue AOD at $550 \mathrm{~nm}$ on 22 April 2015. 

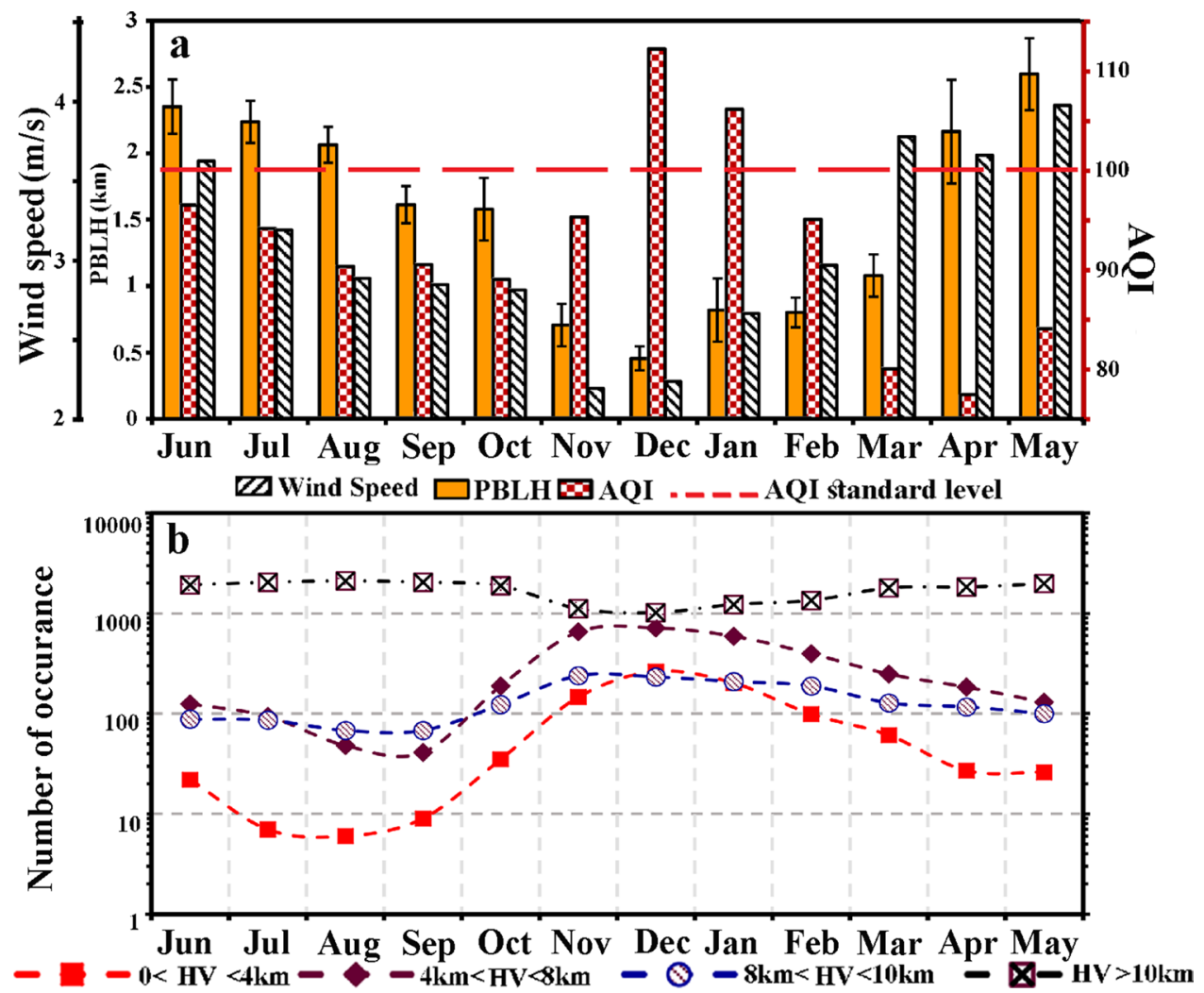

Figure 9. (a) Monthly average of retrieved PBLH during lidar campaign, air quality index (AQI) and surface wind speed over the period between 2010 and 2018. (b) Number of occurrences of the 3-h recorded HV per month by values appeared in the legend of the figure, during years 2010 to 2018.

Terra MODIS on 22 April 2015 (Fig. 8g) clearly indicate the eastward transport of the dust plume towards the Iran Plateau. Due to the movement of this dust plume, AODs over the west and central parts of Iran reach to values even higher than 1.0.

To conclude, the MSG-SEVIRI RGB dust composite, ECMWF reanalysis, MODIS Deep blue AOD, CALIOP depolarization ratio measurements, HYSPLIT backward trajectories, and our lidar measurements have good consistency with each other and confirms that some dust plumes are originated from the regions in the north of the Arabian Peninsula and South Mesopotamia and impacted Tehran.

Boundary layer height evolution. To have a better understanding of atmospheric pollution episodes in Tehran, the planetary boundary layer height (PBLH) is retrieved from lidar recordings ${ }^{38,39}$. The PBLH algorithm, which is explained in "Planetary boundary layer height calculation", is carried out on all lidar recordings and the top height of the polluted boundary layer has extracted for each day during the lidar measurement campaign (Nov. 2014 until Jan. 2016).

Figure 9a illustrates monthly averaged values of the $\mathrm{PBLH}$ which are retrieved from the lidar recordings, monthly averages of air quality index (AQI), and surface wind speed. The AQI is calculated based on the concentrations of different air pollutants (carbon oxides, Nitrogen oxides and PMs) ${ }^{56,57}$. The AQI is averaged over recordings performed on all active AQCC stations in Tehran (Fig. 1a) and surface wind speed data are recorded at Mehrabad station during the years 2010 to 2018. The 3-h HV recordings at the Mehrabad station from 2010 to 2018 are also analyzed and the number of occurrence of events with different HV is shown in Fig. 9b. Events with decreasing HV due to precipitation, are excluded from the data set.

During cold months of the year (Nov.-Feb.), the PBLH remains below $1 \mathrm{~km}$ and even drop to $\sim 500 \mathrm{~m} \mathrm{gl} \mathrm{in}$ December. The monthly average of AQI also raises from Nov. to Feb. This index exceeds the WHO standard level (AQI > 100 means unhealthy air for sensitive group ${ }^{2}$ ) during January and has its peaks in December. All these developments coincide with a decrease of the monthly average of surface wind speed to $\sim 2 \mathrm{~m} / \mathrm{s}$ from Nov. to Dec. On the other hand, during other months with better air quality conditions in which the AQI is below the standard level, the PBLH and the average of surface wind speed increases. Therefore, meteorological factors such as temperature inversion (low PBLH) and stable atmosphere (low wind speed) during cold seasons lead to the accumulation of particulate matters in the planetary boundary layer and eventually cause a reduction of the HV. Figure 9b shows number of days per months, for the 9 years of recordings (2010-2018), when the HV was at four different ranges: $10 \mathrm{~km}<\mathrm{HV}, 8 \mathrm{~km}<\mathrm{HV}<10 \mathrm{~km}, 4 \mathrm{~km}<\mathrm{HV}<8 \mathrm{~km}$, and $\mathrm{HV}<4 \mathrm{~km}$. One can find from Fig. $9 \mathrm{~b}$ that lower values of the HV mostly are happening during November-January. It is noticeable that during winter times anthropogenic activities are responsible for production of more than $70 \%$ of fine particulate ${ }^{6}$. 


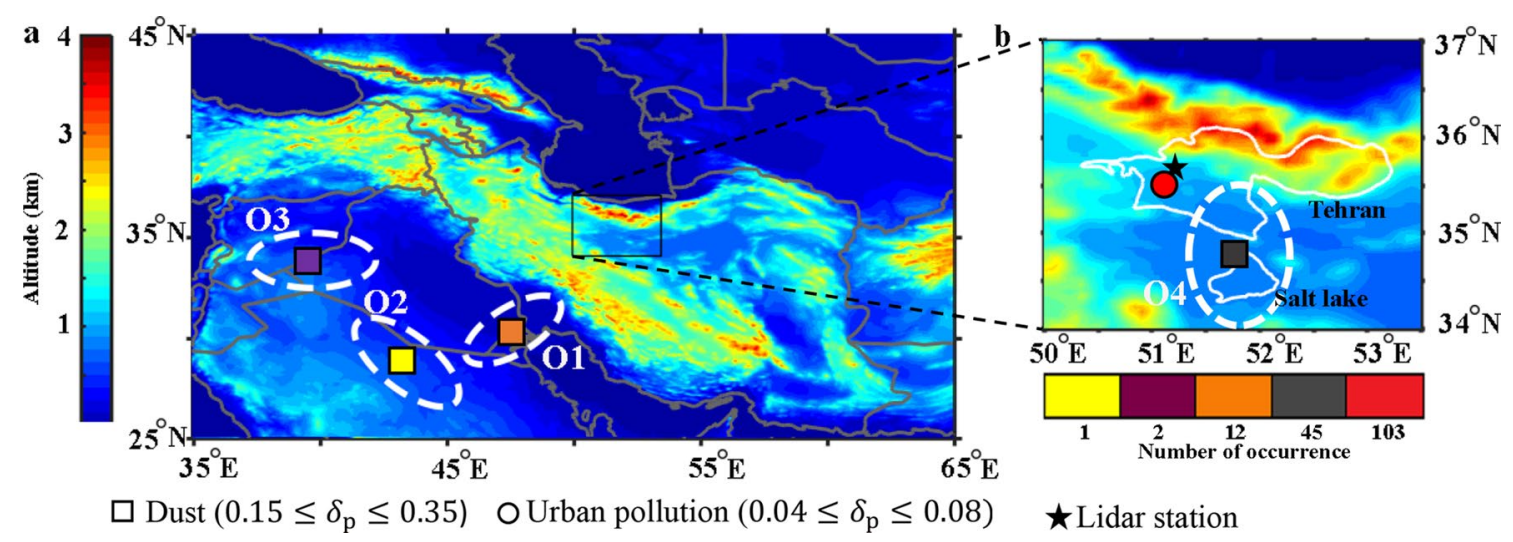

Figure 10. Number of occurrences (horizontal color-bar), approximate origins (white ovals) of the observed dust (squares) and urban pollution (circles) events over Tehran during Nov. 2014 to Jan. 2016 based on lidar measurements, MODIS AOD's and HYSPLIT back trajectories, over the orography map of (a) Iran and its neighboring countries, (b) Tehran province and its neighboring regions.

These reflect the importance of urban-industrial aerosols in atmospheric pollution of Tehran especially during cold months of the year.

Source apportionment. Figure 10 shows distribution of atmospheric aerosol sources that had some impacts over Tehran during the measurement campaign. These sources are specified based on HYSPLIT backward trajectories, together with aerosol type categorization that are retrieved from lidar depolarization ratio recordings. Dashed ovals determine approximate regions of expected sources, and the surface topography is shown in a rainbow color tone in Fig. 10. Borders of the greater Tehran province and the salt lake located on South Tehran are shown in Fig. 10b.

The lidar was in operation for 357 days during the measurement campaign. In this period, there are 163 days in which either $\mathrm{PM}_{2.5}$ or $\mathrm{PM}_{10}$ concentrations are increased above the WHO standard levels ${ }^{2}$. These events are classified as dust (square) or urban pollution (circle) based on the retrieved depolarization ratios for atmospheric particles. Number of events where the atmosphere was polluted with aerosols from different origins are shown in five different colors (Fig. 10). Urban pollution $\left(0.04 \leq \delta_{\mathrm{p}} \leq 0.08\right)$ is the most recorded case (103 cases). It is expected that such particles come from local source in the city. In total, 45 dust events are originated from regions in the south of Tehran (O4 in Fig. 10b). Our recordings show that the Qom-Salt-Lake, in the south of Tehran, had considerable impacts at least on 4 cases of dust events during the measurement campaign. The depolarization ratio for dust cases which are originated from local sources $\left(0.15<\delta_{\mathrm{p}}<0.2\right)$ is lower compared to dust events from external sources $\left(\delta_{\mathrm{p}} \sim 0.31\right)$. During the measurement campaign, the highest recorded depolarization ratio was for a Haboob dust storm outbreaks $\left(\delta_{\mathrm{p}} \sim 0.35\right)$ which its details has not presented in this paper. The number of dust storms which are originated from the south of Mesopotamia (O1) reaches to 12 events. In total, the Arabian Peninsula (O2), Syria and Iraq (O3) are recognized as sources of three dust storms during the measurement campaign.

\section{Summary and conclusion}

For the first time, polarization lidar observations are performed to monitor the highly polluted atmosphere above Tehran, Iran. Lidar measurements are carried on during November 2014 to January 2016. The ultimate outcomes of this study are to determine types, sources, and annual cycles of particulate matters in the atmosphere above Tehran.

To explain the atmospheric pollution condition in Tehran, three cases are discussed as illustrative examples in this article. The first case presents a high load of aerosols in the planetary boundary layer of Tehran's atmosphere, while the particle depolarization ratio of the polluted layer is predominantly low $\left(\delta_{\mathrm{p}} \sim 0.07\right)$. The lidar derived mass concentration of the atmospheric aerosols at the vicinity of the surface is retrieved as $130 \mu \mathrm{g} / \mathrm{m}^{3}$, which is in an acceptable agreement with $\mathrm{P} M_{10} \sim 150 \mu \mathrm{g} / \mathrm{m}^{3}$ reported by the AQCC. These kinds of pollution events usually are happening during the cold months of the year in Tehran (Nov.-Feb.). During these kinds of pollution episodes, the HV drops to $<4 \mathrm{~km}$ and even $<2 \mathrm{~km}$ in Tehran. Case 2 shows how mineral particles $\left(\delta_{\mathrm{p}} \sim 0.17\right)$ from salt lakes in the south of Tehran may impact the atmosphere of the city. The long-range dust transport from Mesopotamia and the Arabian Peninsula toward Tehran is described in the last case. The particle depolarization ratio for such a dust storm is recorded in the range of $0.29 \leq \delta_{\mathrm{p}} \leq 0.34$. During this dust outbreaks, the surface wind speed is increased to $8-10 \mathrm{~m} / \mathrm{s}$, and the HV dropped to $\leq 4 \mathrm{~km}$ in Tehran.

Monthly evolution of the PBLH over Tehran shows a seasonal dependence. From November to February, while atmospheric temperature inversion frequently happens, the PBLH mostly remains below $1 \mathrm{~km}$ and even drops to $\sim 500 \mathrm{~m}$ agl in December (Fig. 9a). Investigation of monthly variations of the PBLH, the AQI and surface wind speed reveals that during air pollution episodes, atmospheric temperature inversion and low wind speed cause that atmosphere becomes completely stable and polluted layers stay close to the ground level and eventually 
lead to high PM concentrations (Fig. 9a). In other words, seasonal variations of meteorological factors besides anthropogenic activities have considerable impacts on urban pollution in Tehran.

During the measurement campaign, there are 103 cases in which pollutant particles are originated from anthropogenic activities. This work also emphasizes that the dry regions in the south of Tehran province, including the Qom dry lake, as origins of 45 recorded dust events, are quite influential on aerosol loading into the atmosphere above Tehran (Fig. 10b). It is interesting that regions in the south of the Mesopotamia (Fig. 10, O2) have considerable impacts on dust contents of the Tehran's atmosphere. Twelve dust events have been recorded with origins from these area during the measurement campaign. From the recordings one may mention two dust events that were originated from the Syrian desert and an intense dust outbreaks with origins in the Al-Nefud desert in the north of the Arabian Peninsula.

Received: 17 May 2020; Accepted: 4 November 2020

Published online: 18 November 2020

\section{References}

1. Statistical Center of Iran. https://www.amar.org.ir/english/Population-and-Housing-Censuses/Census-2016-General-Results. (Accessed 29 February 2020).

2. World Health Organization. Occupational and Environmental Health Team. (2006). WHO Air quality guidelines for particulate matter, ozone, nitrogendioxide and sulfur dioxide: global update 2005: summary of risk assessment. World Health Organization. https://apps.who.int/iris/handle/10665/69477

3. Rezaei, M., Farajzadeh, M., Mielonen, T. \& Ghavidel, Y. Discrimination of aerosol types over the Tehran city using 5 years (20112015) of modis collection 6 aerosol products. J. Environ. Health Sci. Eng. 17, 1-12 (2019).

4. Hosseinpoor, A. R. et al. Air pollution and hospitalization due to angina pectoris in Tehran, Iran: A time-series study. Environ. Res. 99, 126-131 (2005).

5. Khalesifard, H. R. \& Panahifar, H. Monitoring atmospheric particulate matters in Tehran by synergy of lidar measurement, atmospheric models and satellite data. in Light, Energy and the Environment 2015, EM4A.1, https://doi.org/10.1364/EE.2015.EM4A.1 (Optical Society of America, 2015).

6. Arhami, M. et al. Seasonal trends, chemical speciation and source apportionment of fine pm in Tehran. Atmos. Environ. 153, 70-82 (2017).

7. Shahbazi, H., Reyhanian, M., Hosseini, V. \& Afshin, H. The relative contributions of mobile sources to air pollutant emissions in Tehran, Iran: An emission inventory approach. Emission Control Sci. Technol. 2, 44-56 (2016).

8. Zawar-Reza, P., Appelhans, T., Gharaylou, M. \& Shamsipour, A. Mesoscale controls on particulate matter pollution for a mega city in a semi-arid mountainous environment: Tehran, Iran. Int. J. Environ. Pollut. 41, 166-183 (2010).

9. Ginoux, P., Prospero, J. M., Gill, T. E., Hsu, N. C. \& Zhao, M. Global-scale attribution of anthropogenic and natural dust sources and their emission rates based on modis deep blue aerosol products. Rev. Geophys. 50. https://doi.org/10.1029/2012RG000388 (2012).

10. Goudie, A. S. \& Middleton, N. J. Desert Dust in the Global System (Springer Science \& Business Media, New York, 2006).

11. Panahifar, H. \& Khalesifard, H.R. Observation of long-range dust transport from mesopotamia and arabian peninsula toward Tehran, Iran. E3S Web Conf. 99, 02006. https://doi.org/10.1051/e3sconf/20199902006 (2019).

12. Najafpour, N., Afshin, H. \& Firoozabadi, B. The 20-22 february 2016 mineral dust event in Tehran, Iran: Numerical modeling, remote sensing, and in situ measurements. J. Geophys. Res. Atmos. 123, 5038-5058 (2018). https://doi.org/10.1029/2017JD0275 93.

13. Vishkaee, F. A. et al. Dust transport over Iraq and northwest Iran associated with winter shamal: A case study. J. Geophys. Res. Atmos. https://doi.org/10.1029/2011jd016339 (2012).

14. Vishkaee, F. A., Flamant, C., Cuesta, J., Flamant, P. \& Khalesifard, H. R. Multiplatform observations of dust vertical distribution during transport over northwest Iran in the summertime. J. Geophys. Res. https://doi.org/10.1029/2010jd014573 (2011).

15. Ashrafi, K., Shafiepour-Motlagh, M., Aslemand, A. \& Ghader, S. Dust storm simulation over Iran using hysplit. J. Environ. Health Sci. Eng. 12, 9 (2014).

16. Sotoudeheian, S., Salim, R. \& Arhami, M. Impact of middle eastern dust sources on pm10 in Iran: Highlighting the impact of Tigris-Euphrates basin sources and lake Urmia desiccation. J. Geophys. Res. Atmos. 121, 14018-14034 (2016). https://doi. org/10.1002/2016JD025119.

17. Givehchi, R., Arhami, M. \& Tajrishy, M. Contribution of the middle eastern dust source areas to pm10 levels in urban receptors: Case study of Tehran, Iran. Atmos. Environ. 75, 287-295 (2013).

18. Wang, H. et al. Determination and climatology of the diurnal cycle of the atmospheric mixing layer height over Beijing 20132018: Lidar measurements and implications for air pollution. Atmos. Chem. Phys. 20, 8839-8854 (2020). https://doi.org/10.5194/ acp-20-8839-2020.

19. Filioglou, M. et al. Optical and geometrical aerosol particle properties over the United Arab Emirates. Atmos. Chem. Phys. 20, 8909-8922 (2020). https://doi.org/10.5194/acp-20-8909-2020.

20. Hofer, J. et al. Long-term profiling of mineral dust and pollution aerosol with multiwavelength polarization Raman lidar at the central Asian site of Dushanbe, Tajikistan: Case studies. Atmos. Chem. Phys. 17, 14559-14577. https://doi.org/10.5194/acp-1714559-2017 (2017).

21. Li, D., Gross, B., Wu, Y. \& Moshary, F. Correlation study of planetary-boundary-layer-height retrievals from cl51 and chm $15 \mathrm{k}$ ceilometers with application to pm2.5 dynamics in New York city. EPJ Web Conf. 237, 03010. https://doi.org/10.1051/epjconf/20202 3703010 (2020).

22. Heese, B., Baars, H., Bohlmann, S., Althausen, D. \& Deng, R. Continuous vertical aerosol profiling with a multi-wavelength Raman polarization lidar over the pearl river delta, China. Atmos. Chem. Phys. 17, 6679-6691. https://doi.org/10.5194/acp-17-6679-2017 (2017).

23. Burton, S. P. et al. Aerosol classification using airborne high spectral resolution lidar measurements-Methodology and examples. Atmos. Meas. Tech. 5, 73-98. https://doi.org/10.5194/amt-5-73-2012 (2012).

24. Groß, S. et al. Optical properties of long-range transported Saharan dust over Barbados as measured by dual-wavelength depolarization Raman lidar measurements. Atmos. Chem. Phys. 15, 11067-11080. https://doi.org/10.5194/acp-15-11067-2015 (2015).

25. Groß, S. et al. Aerosol classification by airborne high spectral resolution lidar observations. Atmos. Chem. Phys. 13, 2487-2505. https://doi.org/10.5194/acp-13-2487-2013 (2013).

26. Tesche, M. et al. Vertically resolved separation of dust and smoke over cape verde using multiwavelength Raman and polarization lidars during Saharan mineral dust experiment 2008. J. Geophys. Res. Atmos.https://doi.org/10.1029/2009JD011862 (2009).

27. Martonne, E, Chevalier, Aug. \& Cuénot, L. Traite de geographie physique: 3 tomes (Armand Colin, Paris, 1925).

28. Zambakas, J. General climatology. Department of geology. National \& Kapodistrian University of Athens (1992). 
29. Giannakaki, E. et al. The potential of elastic and polarization lidars to retrieve extinction profiles. Atmos. Meas. Tech. 13, 893-905. https://doi.org/10.5194/amt-13-893-2020 (2020).

30. Mamouri, R.-E. \& Ansmann, A. Potential of polarization/Raman lidar to separate fine dust, coarse dust, maritime, and anthropogenic aerosol profiles. Atmos. Meas. Tech. 10, 3403-3427. https://doi.org/10.5194/amt-10-3403-2017 (2017).

31. Mamouri, R. E. \& Ansmann, A. Fine and coarse dust separation with polarization lidar. Atmos. Meas. Tech. 7, 3717-3735. https:// doi.org/10.5194/amt-7-3717-2014 (2014).

32. Klett, J. D. Stable analytical inversion solution for processing lidar returns. Appl. Opt. 20, 211-220 (1981).

33. Freudenthaler, V. et al. Depolarization ratio profiling at several wavelengths in pure Saharan dust during Samum 2006. Tellus B Chem. Phys. Meteorol. 61, 165-179. https://doi.org/10.1111/j.1600-0889.2008.00396.x (2009).

34. Ansmann, A., Seifert, P., Tesche, M. \& Wandinger, U. Profiling of fine and coarse particle mass: Case studies of Saharan dust and Eyjafjallajökull/grimsvötn volcanic plumes. AAtmos. Chem. Phys. 12, 9399-9415. https://doi.org/10.5194/acp-12-9399-2012 (2012).

35. Mamouri, R. E. et al. Low Arabian dust extinction-to-backscatter ratio. Geophys. Res. Lett. 40, 4762-4766. https://doi.org/10.1002/ grl.50898 (2013).

36. Hofer, J. et al. Optical properties of central asian aerosol relevant for spaceborne lidar applications and aerosol typing at 355 and 532 nm. Atmos. Chem. Phys. Discuss. 1-25, 2020. https://doi.org/10.5194/acp-2020-258 (2020).

37. Haarig, M. et al. Dry versus wet marine particle optical properties: Rh dependence of depolarization ratio, backscatter, and extinction from multiwavelength lidar measurements during saltrace. Atmos. Chem. Phys. 17, 14199-14217. https://doi.org/10.5194/ acp-17-14199-2017 (2017).

38. Panahifar, H. \& Khalesifard, H. Tracking atmospheric boundary layer in Tehran using combined lidar remote sensing and ground base measurements. EPJ Web Conf. 176, 06011. https://doi.org/10.1051/epjconf/201817606011 (2018).

39. Baars, H., Ansmann, A., Engelmann, R. \& Althausen, D. Continuous monitoring of the boundary-layer top with lidar. Atmos. Chem. Phys. 8, 7281-7296. https://doi.org/10.5194/acp-8-7281-2008 (2008).

40. Abedinia, O., Amjady, N. \& Ghasemi, A. A new metaheuristic algorithm based on shark smell optimization. Complexity 21, 97-116 (2016).

41. Levy, R. C. et al. The collection 6 modis aerosol products over land and ocean. Atmos. Meas. Tech. 6, 2989-3034. https://doi. org/10.5194/amt-6-2989-2013 (2013).

42. Lyapustin, A. Wang, Y., Korkin, S. \& Huang, D. Modis collection 6 maiac algorithm. Atmos. Meas. Tech. 11, 5741-5765 (2018).

43. Sayer, A. M., Hsu, N. C., Bettenhausen, C. \& Jeong, M.-J. Validation and uncertainty estimates for modis collection 6 "deep blue" aerosol data. J. Geophys. Res. Atmos. 118, 7864-7872. https://doi.org/10.1002/jgrd.50600 (2013).

44. Omar, A. H. et al. Development of global aerosol models using cluster analysis of aerosol robotic network (aeronet) measurements. J. Geophys. Res. Atmos. https://doi.org/10.1029/2004JD004874 (2005).

45. Liu, Z. et al. The CALIPSO Lidar Cloud and Aerosol Discrimination: Version 2 Algorithm and Initial Assessment of Performance. J. Atmos. ocean Technol. 26, 1198-1213. https://doi.org/10.1175/2009JTECHA1229.1 (2005).

46. Knippertz, P. \& Todd, M. C. Mineral dust aerosols over the Sahara: Meteorological controls on emission and transport and implications for modeling. Rev. Geophys. 50. https://doi.org/10.1029/2011RG000362 (2012).

47. Berrisford, P. et al. Atmospheric conservation properties in era-interim. Quart. J. R. Meteorol. Soc. 137, 1381-1399 (2011).

48. Dee, D. P. et al. The era-interim reanalysis: Configuration and performance of the data assimilation system. Quart. J. R. Meteorol. Soc. 137, 553-597 (2011).

49. Stein, A. et al. Noaa’s hysplit atmospheric transport and dispersion modeling system. Bull. Am. Meteorol. Soc. 96, 2059-2077 (2015).

50. Andrews, D. G. An Introduction to Atmospheric Physics (Cambridge University Press, Cambridge, 2010).

51. Ghomashi, F. \& Khalesifard, H. R. Investigation and characterization of atmospheric aerosols over the Urmia lake using the satellite data and synoptic recordings. Atmos. Pollut. Res. https://doi.org/10.1016/j.apr.2020.08.020 (2020).

52. Md, A. S. et al. Columnar-integrated aerosol optical properties and classification of different aerosol types over the semi-arid region, Anantapur, Andhra Pradesh. Sci. Total Environ. 527, 507-519 (2015).

53. Hofer, J. et al. Optical properties of central asian aerosol relevant for spaceborne lidar applications and aerosol typing at 355 and 532 nm. Atmos. Chem. Phys. 20, 9265-9280. https://doi.org/10.5194/acp-20-9265-2020 (2020).

54. Nisantzi, A., Mamouri, R. E., Ansmann, A., Schuster, G. L. \& Hadjimitsis, D. G. Middle east versus Saharan dust extinction-tobackscatter ratios. Atmos. Chem. Phys. 15, 7071-7084. https://doi.org/10.5194/acp-15-7071-2015 (2015).

55. Astitha, M., Lelieveld, J., Abdel Kader, M., Pozzer, A. \& Meij, A. D. Parameterization of dust emissions in the global atmospheric chemistry-climate model emac: Impact of nudging and soil properties. Atmos. Chem. Phys. 12, 11057-11083 (2012).

56. Mintz, D. Technical assistance document for the reporting of daily air quality-the air quality index (aqi). Tech. Research Triangle Park, US Environmental Protection Agency (2009).

57. Kumar, A. \& Goyal, P. Forecasting of air quality in Delhi using principal component regression technique. Atmos. Pollut. Res. 2, 436-444 (2011).

\section{Acknowledgements}

Parts of analyses and visualizations used in this paper were produced with the Giovanni online data system, developed and maintained by the NASA GES DISC. We also acknowledge the MODIS mission scientists and associated NASA personnel for the production of the data used in this research effort. We deeply appreciate the NASA Langley ASDC for the distribution of CALIPSO data. The authors gratefully acknowledge the NOAA Air Resources Laboratory (ARL) for the provision of the HYSPLIT transport and dispersion model. European Organization for the Exploitation of Meteorological Satellites (EUMETSAT) is also acknowledged for data provided by MSG's SEVIRI instrument. Special thanks go to Larry Oolman for kindly providing the surface observations from the University of Wyoming weather center. We are grateful to the AQCC for providing all ground-based particulate matter measurements. We also would like to thank Iran meteorological Organization (IRIMO) for providing synoptic recordings at the Mehrabad station.

\section{Author contributions}

H.P. performed all lidar experiments, lidar data analysis, retrieved satellite data, and wrote manuscript. R.M. participated with a major role in constructing the depolarized lidar, when he was a PhD student at Institute for advanced studies in basic sciences. H.K. directed and supervised the whole project including the design and construction of the lidar and its station, data manipulation, and preparing the manuscript.

\section{Competing interests}

The authors declare no competing interests. 


\section{Additional information}

Supplementary information is available for this paper at https://doi.org/10.1038/s41598-020-76947-W.

Correspondence and requests for materials should be addressed to H.P.

Reprints and permissions information is available at www.nature.com/reprints.

Publisher's note Springer Nature remains neutral with regard to jurisdictional claims in published maps and institutional affiliations.

Open Access This article is licensed under a Creative Commons Attribution 4.0 International License, which permits use, sharing, adaptation, distribution and reproduction in any medium or format, as long as you give appropriate credit to the original author(s) and the source, provide a link to the Creative Commons licence, and indicate if changes were made. The images or other third party material in this article are included in the article's Creative Commons licence, unless indicated otherwise in a credit line to the material. If material is not included in the article's Creative Commons licence and your intended use is not permitted by statutory regulation or exceeds the permitted use, you will need to obtain permission directly from the copyright holder. To view a copy of this licence, visit http://creativecommons.org/licenses/by/4.0/.

(c) The Author(s) 2020 